\title{
Lignocellulose-Degrading Enzymes: A Biotechnology Platform for Ferulic Acid Production from Agro-Industrial Side Streams
}

\author{
Vitalijs Radenkovs ${ }^{1,2 *}$, Karina Juhnevica-Radenkova ${ }^{1}$, Jorens Kviesis ${ }^{3}$, Danija Lazdina ${ }^{1}$, Anda \\ Valdovska ${ }^{4,5}$, Fernando Vallejo ${ }^{6}$, Gunars Lacis ${ }^{2,7}$
}

1 Processing and Biochemistry Department, Institute of Horticulture, Graudu Str. 1, LV-3701 Dobele, Latvia; karina.juhnevica-radenkova@llu.lv (K.J.-R.); danija.lazdina@llu.lv (D.L.)

2 Research Laboratory of Biotechnology, Division of Smart Technologies, Latvia University of Life Sciences and Technologies, Rigas Str. 22, LV-3004 Jelgava, Latvia; vitalijs.radenkovs@llu.lv (V.R.)

3 Department of Environmental Science, University of Latvia, Jelgavas Str. 1, LV-1004 Riga, Latvia; jorens.kviesis@lu.lv (J.K.)

4 Research Laboratory of Biotechnology, Division of Agronomic analysis, Latvia University of Life Sciences and Technologies, Strazdu Str. 1, LV-3002 Jelgava, Latvia; Anda.Valdovska@llu.lv (A.V.)

5 Faculty of Veterinary Medicine, Latvia University of Life Sciences and Technologies, Kr. Helmana Str. 8, LV-3004 Jelgava, Latvia

6 Metabolomics Service, CEBAS-CSIC, University Campus of Espinardo, Edif. 25, 30100 Murcia, Spain; fvallejo@cebas.csic.es (F.V.)

7 Unit of Genetics and Breeding, Institute of Horticulture, Graudu Str. 1, LV-3701 Dobele, Latvia; gunars.lacis@llu.lv (G.L.)

* Correspondence: vitalijs.radenkovs@lvai.lv; Tel.: +371-2865-0011

\begin{abstract}
Biorefining by enzymatic hydrolysis (EH) of lignocellulosic waste material due to low costs and affordability has received enormous interest amongst scientists as a potential strategy suitable for the production of bioactive ingredients and chemicals. In the present study, a sustainable and ecofriendly approach to the extraction of bound ferulic acid (FA) has been demonstrated using a single-step $\mathrm{EH}$ by a mixture of lignocellulose-degrading enzymes. For comparative purposes of the efficiency of $\mathrm{EH}$, an online SFE-SFC-MS extraction and analysis approach was applied. The experimental results demonstrated up to $369.3 \mathrm{mg} 100 \mathrm{~g}^{-1} \mathrm{FA}$ released from rye bran after $48 \mathrm{~h}$ EH with Viscozyme L. The EH of wheat and oat bran with Viscoferm for $48 \mathrm{~h}$ resulted in 255.1 and $33.5 \mathrm{mg} 100 \mathrm{~g}^{-1}$ of FA, respectively. The extraction of FA from bran matrix using the SFE- $\mathrm{CO}_{2}-\mathrm{EtOH}$ delivered up to $464.3 \mathrm{mg} 100 \mathrm{~g}^{-1}$ of FA, though the extractability varied depending on the parameters used. The 10-fold and 30-fold scale-up experiments confirmed the applicability of $\mathrm{EH}$ as a bioprocessing method valid for industrial-scale. The highest yield of FA in both scale-up experiments was obtained from rye bran after $48 \mathrm{~h}$ of $\mathrm{EH}$ with Viscozyme L. In purified extracts, the absence of xylose, arabinose, and glucose as final degradation products of lignocellulose was proven by a HPLC-RID system. Up to $94.0 \%$ purity of FA was achieved by SPE using the polymeric reversed-phase Strata X column and $50 \% \mathrm{EtOH}$ as eluent.
\end{abstract}

Keywords: biorefining; bran; enzymatic hydrolysis; green-extraction; hydroxycinnamates; sustainability; valorization

\section{Introduction}

Cereals make a significant contribution to the economy of the EU, and their by-products are thought to be a potential renewable source of high-demand bioactive compounds. According to FAOSTAT (2021) [1], the global cereal production quantity, incl., barley, maize, millet, oats, rice, rye, sorghum, wheat (average) over the last five decades increased by $240.5 \%$ from 108.3 million tons (Mt) in 1961 to $368.9 \mathrm{Mt}$ in 2019 [1]. Due to their availability, the by-products are getting enormous attention amongst researchers all over the world as a potential and renewable raw material suitable for the manufacturing of active biomolecules and added-value functional ingredients [2]. However, due to a lack of innovations in grainderived by-products processing and existed limitations in effective full-fledged transfer of data from scientific institutions to food processing and pharmaceutical industries, grain by-products still are utilized as feedstuff. The presence of cellulose, hemicellulose, and lignin, the way the bioactive compounds are integrated into the matrix, along with adverse effects on technological processes, the application of bran in the food industry plays a secondary role. Valorization of by-products could be 
done through the application of innovative and green strategies aimed at biomass transformation by extracellularly produced hydrolases such as cellulases, xylanases, and feruloyl esterases, etc.

It has been demonstrated that wheat bran could be used as a raw material for the synthesizes of fumaric acid by enzymatically hydrolyzing (EH) acid pretreated wheat bran with Rhizopus oryzae [3]. Bioconversion of wheat bran-derived ferulic acid (FA) through the utilization of a mixture of commercial enzymes and an E. coli JM109(pBB1) strain could deliver up to $90.0 \mathrm{mg} \mathrm{L}^{-1}$ of vanillin, a flavoring compound that is highly demanded and widely used in the food industry [4]. Within EH of grain-derived by-products, selective production of FA could be achieved by cellulolytic and xylanolytic enzymes that are capable of depolymerizing $\beta$-D-( $1 \rightarrow 4)$-glucosidic and $\beta$-D-( $1 \rightarrow 4)$-xylosidic bonds of cellulose and hemicellulose polymers, respectively [5]. More recently Ferri et al. [6] proposed a sequential treatment of thermally pretreated wheat bran for the selective release of FA through the application of a blend of proteolytic, amylolytic, and cellulolytic enzymes. The authors highlighted the efficiency of developed technology, since a 40-fold scale-up EH process has given a satisfactory yield of FA. These results were further confirmed by Martín-Diana et al. [7], demonstrating ability of multi-active $\beta$-glucanase and $\beta$ xylanase enzyme complex Ultraflo XL to release FA from wheat bran under optimal conditions.

Rye bran is less explored, however, likewise to wheat, it can be biorefined and further used as a source of such bioactives as alkylresorcinols, benzoxazinoids, and phenolic acids [8]. This assertion has already been reinforced by Kapreliants and Zhurlova [9], indicating that biomodification of rye bran within stepwise EH of thermally and mechanically pretreated bran material aided in biotechnologically obtaining high-value bioactives, i.e., leucine, arginine, valine. Similarly to wheat, the hydroxycinnamates (HCMs) in the rye bran (FA specifically) are present as components of the outer layer of the kernel, which are located in outer and inner pericarps, seed coats (testa), hyaline, and aleurone layers, and are tightly attached to hemicellulose through ester bonds [10]. The ratio of free to bound FA in rye arabinose-xylose (hemicellulose) fraction is 0.1:1000, indicating a strong binding affinity of this molecule to other macronutrients. The report of Konopka et al. (2014) [11] revealed the presence of $0.0082 \mathrm{mg}^{100 \mathrm{~g}^{-1}}$ free FA in whole rye grain flour, pointing to the relative abundance of this phenolic acid in rye grain in relation to other cinnamates. Alkaline-assisted hydrolysis with subsequent solid-liquid or liquid-liquid extraction seems to be a feasible solution to release bound forms. The report of Andreasen et al. [12]

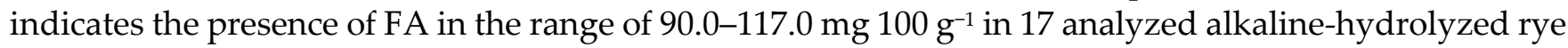
varieties. Inconsistent results, however, were reported by Buksa et al. [13], showing that the content of FA after $24 \mathrm{~h}$ alkaline-assisted hydrolysis of a fraction rich in arabinoxylans was found to be considerably lower than that of non-treated samples. The authors pointed out to harsh conditions during hydrolysis had led to the quantitative and qualitative loss of phenolic acids, incl., FA. A similar observation has been made by [14], indicating the formation of 4-vinylguaiacol as the first degradation product of FA that appeared during alkaline hydrolysis.

Although the release of FA using alkaline-assisted hydrolysis of bran material is high, unluckily its production under industrial scale requires substantial input of strong alkalis and acids, however, regarding already existing greenhouse gas emission problems, production and utilization of strong bases or acids would adversely affect human health, the environment, and industry. In a recent study of Juhnevica-Radenkova et al. [14], up to $135.6 \%$ of the total alkaline-extractable FA release was achieved from rye bran after EH with a sole multi-enzyme complex Viscozyme L. However, this is the only report highlighting the release of FA during EH with lignocellulose-degrading enzymes from rye bran available so far.

Oats, due to their nutritional composition and availability of multiple bioactive compounds, such as $\beta$-glucan, avenanthramides, tocopherols and tocotrienols, phytosterols, phytic acid, and avenacosides, are reported to have beneficial effects on human health, incl. reduction of cardiovascular diseases, type 2 diabetes mellitus, gastrointestinal disorders and cancer risk [15]. It has been stated that among phenolic compounds, FA is found to be the dominant HCM in oat, however, similarly to wheat and rye, is integrated into the matrix of the three-dimensional structure of cellulose, hemicellulose, and lignin, forming strong ester or ether linkages with it [16]. The report of Zhao and Moghadasian [17] reveals that whole oats may contain from 25-35 mg $100 \mathrm{~g}^{-1}$ of FA, while oat bran $33.0 \mathrm{mg} 100 \mathrm{~g}^{-1}$, however, growing conditions and variety are the main factors determining the amount of FA. 
In the context of the "EU Green deal" process, EH eliminates the use of toxic and/ or corrosive chemicals and, due to relative simplicity in operational conditions could represent the future strategy for the production of compounds that are currently manufactured by chemical routs.

The limited information on the recovery of FA and other HCMs from rye, wheat, and oat bran by means of green processing technologies promoted the design of this study, focusing on the evaluation of the release of FA from bran as a result of biorefining accomplished by three lignocellulose-degrading enzymes.

\section{Materials and Methods}

\subsection{Plant Material}

Three types of commercial food-grade bran samples were obtained from a local supplier the Ltd. "Voldemars", separated as rye (Secale cereále L.), wheat (Triticum aestívum L.), and oat (Avena sativa L). Based on morphological evaluation, such hydrological layers as outer pericarp, inner pericarp (cross cells, tube cells), seed coat (testa), hyaline, and aleurone layers with attached starch granules were identified in the bran samples. The proximate composition of the bran samples is shown in Table 1.

Table 1. Nutritional composition of bran by-products derived from rye, wheat and oat grains, $g$ $100 \mathrm{~g}^{-1} \mathrm{DW}$.

\begin{tabular}{|c|c|c|c|c|c|c|c|c|}
\hline \multicolumn{9}{|c|}{ Major Nutrients Profile, g $100 \mathrm{~g}^{-1} \mathrm{DW}$} \\
\hline \multirow[b]{2}{*}{$\begin{array}{l}\text { Type of } \\
\text { Bran }\end{array}$} & \multirow[b]{2}{*}{ Moisture, $\%$} & \multirow[b]{2}{*}{$\mathrm{CH}$} & \multirow[b]{2}{*}{$\begin{array}{l}\text { Crude } \\
\text { Lipids }\end{array}$} & \multirow[b]{2}{*}{$\begin{array}{l}\text { Crude } \\
\text { Proteins }\end{array}$} & \multirow[b]{2}{*}{ DF } & \multicolumn{3}{|c|}{ FA, mg $100 \mathrm{~g}^{-1}$} \\
\hline & & & & & & Free & $\begin{array}{l}\text { Thermally } \\
\text { processed }\end{array}$ & $\begin{array}{c}\text { Alkali- } \\
\text { hydrolyzed }\end{array}$ \\
\hline Rye & $11.7 \pm 0.2^{a}$ & $30.9 \pm 0.5^{b}$ & $3.8 \pm 0.1^{\mathrm{c}}$ & $16.9 \pm 0.5^{\mathrm{a}}$ & $36.0 \pm 1.9^{b}$ & $19.6 \pm 0.6^{b}$ & $14.2 \pm 0.1^{b}$ & $171.2 \pm 3.2^{b}$ \\
\hline Wheat & $11.9 \pm 0.2^{\mathrm{a}}$ & $20.3 \pm 0.4^{c}$ & $4.5 \pm 0.1^{b}$ & $16.2 \pm 0.4^{a}$ & $46.5 \pm 2.1^{a}$ & $32.1 \pm 0.7 \mathrm{a}$ & $19.9 \pm 0.1^{a}$ & $273.3 \pm 4.1^{a}$ \\
\hline Oat & $12.4 \pm 0.3^{a}$ & $50.0 \pm 0.9^{a}$ & $6.7 \pm 0.5^{\mathrm{a}}$ & $14.0 \pm 0.7^{b}$ & $14.0 \pm 1.7 \mathrm{c}$ & $5.7 \pm 0.1^{c}$ & $10.5 \pm 0.1^{\mathrm{c}}$ & 45.7. $\pm 1.9^{\mathrm{c}}$ \\
\hline
\end{tabular}

Note: Values are means \pm SD values of three replicates $(n=\mathrm{e})$. Means within the same column with different superscript letters $(\mathrm{a}, \mathrm{b}$, and $\mathrm{c}$ ) are significantly different at $p<0.05$; DW - dry weight; $\mathrm{CH}$ - carbohydrates; DF - dietary fiber. Free, thermally processed, and alkali-hydrolyzed refer to the extraction of FA from bran material based on solid-liquid extraction and alkaline-assisted hydrolysis following the methodology described by Juhnevica-Radenkova et al. [14].

\subsection{Plant Material Preparation for Alkaline and Enzymatic Hydrolysis and Analysis of Hydroxycinnamates}

Each bran sample before $\mathrm{EH}$ was ground to reach $\varnothing 0.5 \mathrm{~mm}$ particle size using a variable speed rotor mill "KN 295 Knifetec $^{\mathrm{TM} "}$ (FOSS, Hilleroed, Denmark) and defatted following the methodology described by Radenkovs et al. [18]. Inactivation of native microorganisms and enzymes was done by mixing bran samples with double distilled water (DDW) at a ratio of 1:10 (w/v) in $25 \mathrm{~mL}$ reagent bottles with screw caps (VWR ${ }^{\mathrm{TM}}$, International, $\mathrm{GmbH}$, Darmstadt, Germany) with the following subjecting to autoclaving using a digital autoclave with counter-pressure "Raypa, AES 110" (Barcelona, Spain) for 10 $\min$ at $121 \pm 1{ }^{\circ} \mathrm{C}$ temperature and counter pressure 2.0 Pa. After thermal processing, the liquid fraction was decanted for further HPLC analysis (the impact of thermal processing), while solids were freezedried using a "Christ Alpha 1-2 LDplus" freeze-drying system (Osterode near Harz, Germany) at -51 \pm $1{ }^{\circ} \mathrm{C}$ under a vacuum of $0.070-0.080 \mathrm{mBar}$ for $72 \mathrm{~h}$. Dried samples were packed in polypropylene ziplock silver bags (high-density polyethylene polymer, density $3 \mathrm{~mm}$, Impak Co., Los Angeles, CA, USA) ( $200 \mathrm{~g}$ in each) and stored at a temperature of $-18 \pm 1{ }^{\circ} \mathrm{C}$ until further analysis and use for a maximum of 6 wk. Moisture content was analyzed gravimetrically as proposed by Ruiz [19]

\subsection{Chemicals and Reagents}

Commercial standards, i.e., caffeic acid (CA), trans-isomer of ferulic acid ( $t$-FA) and trans-isomer of iso-FA ( $t$-iso-FA), vanillic acid (VA), vanillin $(\mathrm{VN}), p$-coumaric acid ( $p$-CA), trans-cinnamic acid ( $t$-CA), $(-)$-epicatechin, $( \pm)$-catechin, gallic acid (GA), sinapic acid (SA), syringic acid (SIA), protocatechuic acid (PCA), 4-vinylphenol (4-VP), 2-methoxy-4-vinylphenol (4-VG), eugenol (EGN), neochlorogenic (NCGA) and chlorogenic acids (CGA), rhamnose, ribose, xylose, arabinose, sorbose, fructose, mannose, glucose, galactose, sucrose, maltose, lactose, and glycerol were purchased from Sigma-Aldrich Chemie Ltd., 
(Steinheim, Germany). A standard solution containing mixture of $\mathrm{C}_{4}-\mathrm{C}_{24}$ fatty acid methyl esters (FAMEs) with purity $\geq 99.0 \%$ were acquired from Sigma-Aldrich Chemie Ltd. Sodium hydroxide $(\mathrm{NaOH})$, potassium hydroxide $(\mathrm{KOH})$, citric acid $\left(\mathrm{C}_{6} \mathrm{H}_{8} \mathrm{O}_{7}\right)$, 2,2-diphenyl-1-picrylhydrazyl, sodium citrate dihydrate $\left(\mathrm{C}_{6} \mathrm{H}_{5} \mathrm{Na}_{3} \mathrm{O}_{7} \cdot 2 \mathrm{H}_{2} \mathrm{O}\right)$, phenolphthalein $\left(\mathrm{C}_{20} \mathrm{H}_{14} \mathrm{O}_{4}\right)$, 0.5M trimethylphenylammonium hydroxide solution $\left(\mathrm{CH}_{3}\right)_{3} \mathrm{~N}(\mathrm{OH}) \mathrm{C}_{6} \mathrm{H}_{5}(\mathrm{TMPAH})$ in methanol $(\mathrm{MeOH})$ for $\mathrm{GC}$ derivatization were of reagent grade. Ethanol $(\mathrm{EtOH}), \mathrm{MeOH}$, acetonitrile $(\mathrm{MeCN})$, formic acid $(\mathrm{HCOOH})$ (puriss r.a.), and ammonium formate $\left(\mathrm{HCO}_{2} \mathrm{NH}_{4}\right)$ of LC-MS grade were purchased from Merck KGaA (Darmstadt, Germany). HPLC grade diethyl ether $\left(\mathrm{C}_{2} \mathrm{H}_{5}\right)$ and $n$-hexane $\left(\mathrm{C}_{6} \mathrm{H}_{14}\right)$, pyridine $\left(\mathrm{C}_{5} \mathrm{H}_{5} \mathrm{~N}\right)$ were purchased from Merck KGaA. The ultrapure water was produced using the reverse osmosis PureLab Flex Elga water purification system (Veolia Water Technologies, Paris, France).

\subsection{Enzymes}

Industrial non-starch polysaccharide (N-SPs) degrading enzyme preparations have been kindly provided by the company Novozymes ${ }^{\circledR}$ (Bagsvaerd, Denmark) for laboratory purposes. Since each preparation selected is a multi-enzyme complex containing various cellulolytic and xylanolytic enzymes, in this study they were applied independently, not as a mixture. A list of enzymes used is given in Table 2 .

Table 2. The list of commercial hydrolytic enzymes used in this study.

\begin{tabular}{ccccc}
\hline $\begin{array}{c}\text { Commercial } \\
\text { Enzyme }\end{array}$ & $\begin{array}{c}\text { Declared } \\
\text { Activity }\end{array}$ & $\begin{array}{c}\text { Enzyme } \\
\text { Activity }\end{array}$ & Source & EC number \\
\hline \multirow{2}{*}{ Viscoferm $^{\circledR}$} & \multirow{2}{*}{$222 \mathrm{FBG} \mathrm{g}^{-1}$} & $\begin{array}{c}\text { endo-1,4- } \beta \text {-xylanase } \\
\text { endo-1,3-(1,4)- } \beta \text {-D-glucanase }\end{array}$ & Aspergillus spp. & 3.2 .1 .8 \\
& & endo-1,4- $\beta$-xylanase & & 3.2 .1 .4 \\
\hline \multirow{2}{*}{ Viscozyme $^{\circledR} \mathrm{L}$} & \multirow{2}{*}{$100 \mathrm{FBG} \mathrm{g}^{-1}$} & $\begin{array}{c}\text { non-reducing end } \alpha \text {-L- } \\
\text { arabinofuranosidase }\end{array}$ & Aspergillus aculeatus & 3.2 .1 .8 \\
& & endo-1,4- $\beta$-D-glucanase & & 3.2 .1 .4 \\
\hline Celluclast $^{\circledR} 1.5 \mathrm{~L}$ & $700 \mathrm{EGU} \mathrm{g}^{-1}$ & endo-1,4- $\beta$-D-glucanase & Trichoderma reesei & 3.2 .1 .4 \\
\hline
\end{tabular}

Note: EC - enzyme commission; EGU - endoglucanase units; FBG-fungal $\beta$-glucanase units.

\subsection{Enzymatic Hydrolysis of Rye, Wheat, and Oat Bran}

EH of bran samples employing biocatalysts was done in a water bath "SW23" with a capacity of 20.0 $\mathrm{L}$ and a horizontal shaking system, and thermostatic and temporal control system (Julabo ${ }^{\circledR}$, ZalbahaHinterglemm, Germany). To estimate the influence of treatment time on the yield of HCMs (FA specifically), the process was done within the range of $12-72 \mathrm{~h}$. The optimal conditions for each enzyme were chosen individually based on the Novozymes ${ }^{\circledR}$ recommendations and following the protocol described by Juhnevica-Radenkova et al. [14]. The EH of N-SPs, i.e., cellulose and hemicellulose was accomplished utilizing three commercially available multi-enzyme complexes, i.e., Viscozyme L, Celluclast 1.5 L, or Viscoferm. For this purpose, $10 \mathrm{~mL} 0.5 \mathrm{M}$ sodium citrate buffer ( $\mathrm{pH}$ 4.6) containing 6 FBG mL $\mathrm{m}^{-1}$ of endo-1,4- $\beta$-xylanase (Viscozyme L or Viscoferm), or 10 EGU mL $\mathrm{m}^{-1}$ of endo-1,4- $\beta$-D-glucanase (Celluclas $1.5 \mathrm{~L}$ ) was added to $1 \mathrm{~g}$ of each bran sample. The mixture was then vortexed for 2 min using the "ZX3" vortex mixer (Velp ${ }^{\circledR}$ Scientifica, Usmate Velate, Italy) and incubated in a water bath at $44 \pm 1$ ${ }^{\circ} \mathrm{C}$ and $100 \mathrm{rpm}$. The release of HCMs at different time points, i.e., 12, 24, 48, and $72 \mathrm{~h}$ of EH was ascertained chromatographically. To terminate the reaction prior to analysis, each aliquot harvested was subjected to ultrasonication at $50 \mathrm{kHz}$ with output wattage of $360 \mathrm{~W}$ for $10 \mathrm{~min}$ at $25 \pm 1{ }^{\circ} \mathrm{C}$ using a "Ultrasons" ultrasonic bath (J.P. Selecta ${ }^{\circledR}$, Barcelona, Spain), followed by centrifugation at 20,160× $\mathrm{g}$ for $10 \mathrm{~min}$ at $25 \pm 1{ }^{\circ} \mathrm{C}$ in a "Hermle Z $36 \mathrm{HK}^{\prime \prime}$ centrifuge (Hermle Labortechnik, GmbH, Wehingen, Germany) and filtration using a $0.22 \mu \mathrm{m}$ polyvinylidene fluoride (PVDF) hydrophilic membrane filter (Durapore, Millipore, Billerica, MA, USA).

\subsection{Hydrolysis of Bran Samples under 10- and 30-fold Scale-Up Process}

For FA release from bran matrix, scale-up experiments were performed using the "New Brunswick Bioflo/Celligen 115" bioreactor (Eppendorf, Hamburg, Germany). The process was carried out in a $2.5 \mathrm{~L}$ 
glass vessel at the scale of 10 and $30 \mathrm{~g}$ of bran. The same ratio of buffer to substrate was used. During $\mathrm{EH}$, the prepared mixture was continuously stirred at $100 \mathrm{rpm}$ using the Rushton impeller. The $\mathrm{pH}$ of the mixture was maintained at 4.6 by the proportional and integral controller which operates peristaltic pumps, assigned to perform acid or base addition. The measurements of $\mathrm{pH}$ were done by a gel-filled $\mathrm{pH}$ probe (Eppendorf, Hamburg, Germany). The release of HCMs at different time points, i.e., 12, 24, 48, and $72 \mathrm{~h}$, of $\mathrm{EH}$ was ascertained chromatographically within $2 \mathrm{~h}$. The obtained hydrolysates were ultrasonicated at $50 \mathrm{kHz}$ for $10 \mathrm{~min}$ at $25 \pm 1{ }^{\circ} \mathrm{C}$ and filtered through a $0.22 \mu \mathrm{m}$ PVDF before chromatographic analysis.

\subsection{Recovery of FA from Bran Hydrolysates by Solid-Phase Extraction}

The FA was extracted from rye bran hydrolysates following a protocol provided by Phenomenex with minor modifications. Briefly, $3 \mathrm{~mL}$ of bran hydrolysate was spiked with an internal standard (3,5dichloro-4-hydroxybenzoic acid), followed by filtration through a $0.45 \mu \mathrm{m}$ PVDF membrane filter. Recovery of FA was done using solid-phase extraction (SPE) "Strata-X" column (Phenomenex, Torrance,

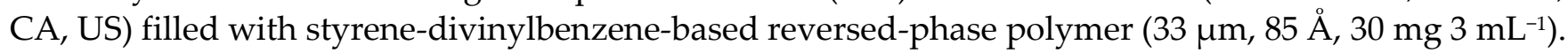
Conditioning/ equilibration of SPE column was done by 1 column volume of pure $\mathrm{MeOH}$, followed by 1 volume of DDW. The loaded sample was washed with 1 column volume of DDW and a flow-through fraction was collected for further chromatographic work and analysis. Analyte elution was done by 2 volumes of either acidified absolute $\mathrm{MeOH}$ or $\mathrm{EtOH}(2 \%$ formic acid $v / v)$ or their aqueous solutions. Collected eluate fractions were subjected to drying under a gentle stream of $\mathrm{N}_{2}$ to complete dryness. The dried samples were reconstituted in $1 \mathrm{~mL}$ of $80 \%$ acidified $\mathrm{MeOH}$ (MeOH:DDW:formic acid ratio 80:19:1 v/v/v).

\subsection{Plant Material Preparation for SFE-SFC Extraction of Hydroxycinnamates}

Duplicate samples of $100 \pm 1.0 \mathrm{mg}$ of dried and ground $(\varnothing \leq 0.5 \mathrm{~mm}$ particle size) bran material were weighed into $5 \mathrm{~mL}$ stainless steel extraction cells (Tokyo, Japan) with cellulose discs at the bottom and top. The extraction vessel was placed in the rack changer of the SFE apparatus. Liquid $\mathrm{CO}_{2}$ and $\mathrm{EtOH}$ as a co-solvent (modifier) were delivered through pumps into the extraction vessel and changed to supercritical fluid by adjusting temperature and pressure.

Variations in extraction conditions used in experiments to assess the release HCMs are depicted in Table 3, while other parameters are as follows: the extraction solvent consisted of solvent A supercritical fluid of $\mathrm{CO}_{2}$ (AGA, Latvia, purity > 99.0); and solvent B (modifier) - EtOH (purity 96.8\%); delivered to extraction vessel at flow rate $5.4 \mathrm{~mL} \mathrm{~min}^{-1}$ using a back pressure regulator $\mathrm{A}-14.7 \mathrm{MPa}$ and back pressure regulator $\mathrm{B}-15.0 \mathrm{MPa}$ both operated at $50^{\circ} \mathrm{C}$. 
Table 3. The experimental layout using orthogonal array design.

\begin{tabular}{ccccc}
\hline $\begin{array}{c}\text { Experiment } \\
\text { No. }\end{array}$ & Temperature, ${ }^{\circ} \mathbf{C}$ & Pressure, MPa & $\begin{array}{c}\text { Co-solvent } \\
\text { concentration, } \%\end{array}$ & $\begin{array}{c}\text { Extrication time (static to } \\
\text { dynamic mode), min }\end{array}$ \\
\hline \hline 1 & $\mathbf{4 0}$ & 15 & 10 & $3: 3$ \\
2 & $\mathbf{4 5}$ & 15 & 10 & $3: 3$ \\
3 & $\mathbf{5 0}$ & 15 & 10 & $3: 3$ \\
4 & $\mathbf{6 0}$ & 15 & 10 & $3: 3$ \\
\hline 5 & 50 & $\mathbf{1 0}$ & 10 & $3: 3$ \\
6 & 50 & $\mathbf{1 5}$ & 10 & $3: 3$ \\
7 & 50 & $\mathbf{2 0}$ & 10 & $3: 3$ \\
8 & 50 & $\mathbf{2 5}$ & 10 & $3: 3$ \\
\hline 9 & 50 & 15 & 7.5 & $3: 3$ \\
10 & 50 & 15 & $\mathbf{1 0}$ & $3: 3$ \\
11 & 50 & 15 & $\mathbf{1 5}$ & $3: 3$ \\
12 & 50 & 15 & $\mathbf{2 0}$ & $\mathbf{3}$ \\
\hline 13 & 50 & 15 & 10 & $\mathbf{1}$ \\
14 & 50 & 15 & 10 & $\mathbf{2}$ \\
15 & 50 & 15 & 10 & $\mathbf{3}$ \\
16 & 50 & 15 & 10 & $\mathbf{3}$ \\
17 & 50 & 15 & 10 & $\mathbf{2}$ \\
\hline
\end{tabular}

\subsection{The online SFE-SFC Extraction Conditions for Hydroxycinnamates}

Along with alkaline hydrolysis, the protocol described in detail by Juhnevica-Radenkova et al. [14], the online extraction, separation, and analysis of HCMs by means of supercritical-fluid extractionsupercritical fluid chromatography (SFE-SFE) coupled to QqQ-MS 8050 mass selective detector was used in this experiment.

The online SFE-SFC-MS-TQ extraction and analysis was done using the "Nexera UC" SFE-SFC-LC system (Shimadzu Corporation, Tokyo, Japan) with the following configuration: SFE-30A (SFE module), LC-30ADSF ( $\mathrm{CO}_{2}$ deliver pump), LC-40DX3 (modifier deliver pump), DGU-405 (degassing unit), CTO40AC (column oven), SFC-30A×2 (back pressure adjustment module), Rack Changer II, QqQ-MS-8050 (mass selective detector), SCL-40 (system controller), LabSolutions Insight LC-MS version 3.7 SP3 (workstation), shown in Figure 1.

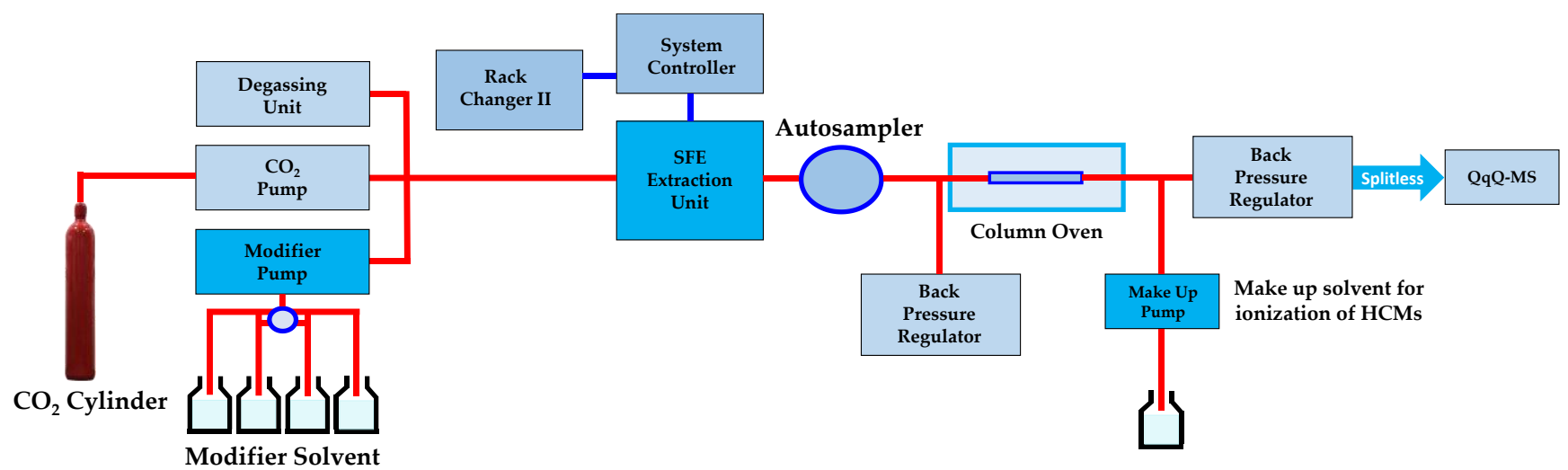

Figure 1. Schematic representation of the online supercritical fluid extraction-supercritical fluid chromatography-mass spectrometry (SFE- SFC-MS-TQ).

\subsection{The Online SFE-SFC-MS-TQ Analytical Conditions for Hydroxycinnamates}

Chromatographic separation of HCMs was carried out using a reversed-phase Shim-pack UC-RP column $\left(5.0 \mu \mathrm{m}, 250 \times 4.6 \mathrm{~mm}\right.$; Tokyo, Japan) operating at $45^{\circ} \mathrm{C}$ and a flow rate of $1.0 \mathrm{~mL} \mathrm{~min}^{-1}$. The mobile phase used was supercritical fluid of $\mathrm{CO}_{2}(\mathrm{~A})$ and acidified $\mathrm{MeOH}(0.002 \%$ formic acid, $v / v)$ with $5 \mathrm{mM}$ ammonium formate (B). Separation of HCMs was done using the following gradient conditions: elution started with $10 \% \mathrm{~B}$ to obtain $40 \% \mathrm{~B}$ at $11 \mathrm{~min}, 60 \% \mathrm{~B}$ at $15 \mathrm{~min}, 10 \% \mathrm{~B}$ at $17 \mathrm{~min}$, with the following $2 \mathrm{~min}$ wash and equilibration. A make-up solution consisting of $5 \mathrm{mM}$ ammonium formate in $\mathrm{MeOH}$ 
was delivered with a make-up pump after column separation to promote HCMs ionization. Data was acquired using a LabSolutions Insight software, which was also used for instrument control and processing. The system was operated using both negative and positive ion polarity, and data was acquired in centroid and profile mode, with a data storage threshold of 5000 absorbance for MS. The operating conditions were as follows: detector voltage $-1.8 \mathrm{kV}$, conversion dynode voltage $-10.0 \mathrm{kV}$, interface voltage $-4.0 \mathrm{kV}$, interface temperature $-300{ }^{\circ} \mathrm{C}$, desolvation line temperature $-250{ }^{\circ} \mathrm{C}$, heat block temperature $-400{ }^{\circ} \mathrm{C}$, nebulizing gas - argon (Ar, purity-99.9\%, ) at flow $-3.0 \mathrm{~L} \mathrm{~min}^{-1}$, heating gas - carbon dioxide $\left(\mathrm{CO}_{2}\right.$, purity - 99.0\%, ) at flow - $10.0 \mathrm{~L} \mathrm{~min}^{-1}$, drying gas - nitrogen $\left(\mathrm{N}_{2}\right.$, the drying gas was separated from the air using a nitrogen generator system from Peak Scientific Instruments Ltd. (Inchinnan, Scotland, UK, purity - 99.0\%) at flow - $10.0 \mathrm{~L} \mathrm{~min}^{-1}$. All HCMs were monitored in the scheduled multiple reaction monitoring (MRM) mode. A list of all MRM transitions, collision energy, Q1, Q3, and dwell time for phenolic compounds is depicted in Table 4.

\subsection{The HPLC-ESI-QqQ-MS Analytical Conditions for Phenolics}

The analyses were carried out using a Shimadzu series Nexera UC SFC-SFE-LC system (Tokyo, Japan) coupled to a triple quadrupole (QqQ) mass selective detector MS-8050 (Tokyo, Japan) with an electrospray ionization interface (ESI). Sample of $1 \mu \mathrm{L}$ was injected onto a reversed-phase Shim-pack UC-RP column $\left(5.0 \mu \mathrm{m}, 250 \times 4.6 \mathrm{~mm}\right.$; Tokyo, Japan) operating at $45^{\circ} \mathrm{C}$ and a flow rate of $1.0 \mathrm{~mL} \mathrm{~min}^{-1}$. The mobile phases used were acidified DDW $(0.002 \%$ formic acid, $v / v)$ supplemented with $5 \mathrm{mM}$ ammonium formate (A) and acidified $\mathrm{MeOH}$ with $5 \mathrm{mM}$ ammonium formate $(0.002 \%$ formic acid, $v / v)$ (B). Separation of compounds was done using the following gradient conditions: elution started with $5 \%$ B to obtain $10 \%$ B at $5 \mathrm{~min}, 60 \% \mathrm{~B}$ at $12-15 \mathrm{~min}, 10 \% \mathrm{~B}$ at $18 \mathrm{~min}$. Furthermore, $\mathrm{MeOH}$ injections were included every three samples as a blank run to avoid the carry-over effect. Data acquisition, analysis, and processing were done similarly as for the online SFE-SFC-MS-TQ analytical conditions for hydroxycinnamates (section 2.10.).

\subsection{The HPLC-RID Analytical Conditions for Carbohydrates}

The quantitative analysis of mono- and disaccharides, the hydrolysates along with appropriate calibration standards were run on a Waters Alliance HPLC system (model No. e2695) equipped with a 2414 RI detector and a 2998 column heater (Waters Corporation, Milford, MA). Chromatographic separation was done on an Altima Amino $\left(4.6 \times 250 \mathrm{~mm} ; 5 \mu \mathrm{m}\right.$; Grace ${ }^{\mathrm{TM}}$, Columbia, MD, USA) column. A column and flow cell temperature was maintained at $30^{\circ} \mathrm{C}$. A mixture of DDW and $\mathrm{CH}_{3} \mathrm{CN}(80: 20$, $v / v)$ was used as a mobile phase in isocratic mode. The flow rate of the mobile phase was $1.0 \mathrm{~mL} \mathrm{~min}^{-1}$. The injection volume was $15 \mu \mathrm{L}$. System control, data acquisition, analysis, and processing were done by Empower 2 Chromatography Data Software (Waters Corporation). 
Table 4. MRM transitions, collision energy, Q1, Q3 and dwell time for investigated hydroxycinnamates.

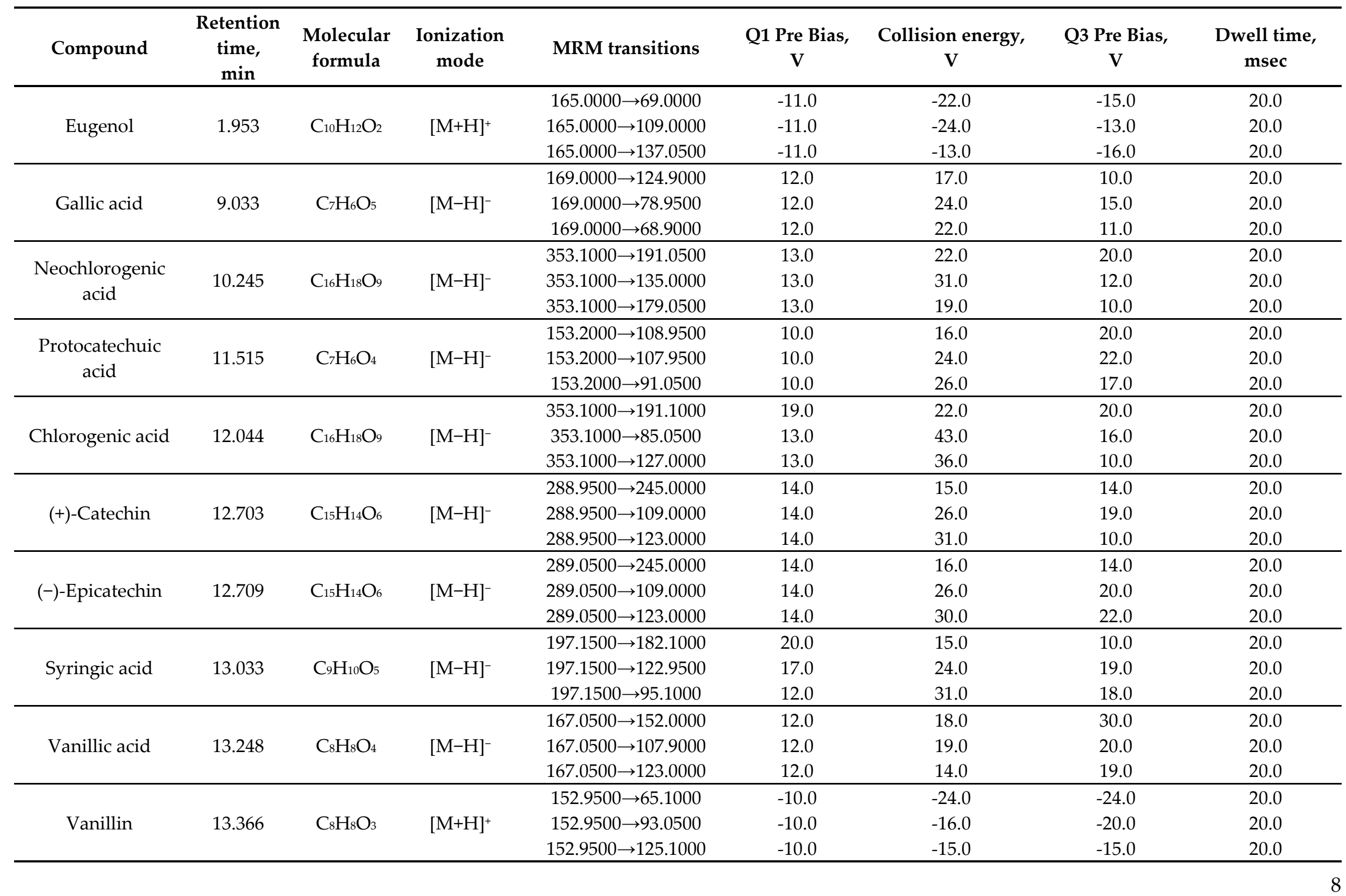




\section{Table 4 continuation.}

\begin{tabular}{|c|c|c|c|c|c|c|c|c|}
\hline Compound & $\begin{array}{c}\text { Retention } \\
\text { time, } \\
\text { min } \\
\end{array}$ & $\begin{array}{l}\text { Molecular } \\
\text { formula }\end{array}$ & $\begin{array}{l}\text { Ionization } \\
\text { mode }\end{array}$ & MRM transitions & $\begin{array}{c}\text { Q1 Pre Bias, } \\
\text { V }\end{array}$ & $\begin{array}{c}\text { Collision } \\
\text { energy, } \\
\text { V } \\
\end{array}$ & $\begin{array}{c}\text { Q3 Pre Bias, } \\
\text { V }\end{array}$ & $\begin{array}{c}\text { Dwell time, } \\
\text { msec }\end{array}$ \\
\hline \multirow[t]{3}{*}{ 4-Vinylphenol } & \multirow{3}{*}{13.747} & \multirow{3}{*}{$\mathrm{C}_{8} \mathrm{H}_{8} \mathrm{O}$} & \multirow{3}{*}[\mathrm{M}+\mathrm{H}]{$^{+}$} & $121.0500 \rightarrow 77.2000$ & -20.0 & -23.0 & -16.0 & 20.0 \\
\hline & & & & $121.0500 \rightarrow 91.2000$ & -21.0 & -19.0 & -18.0 & 20.0 \\
\hline & & & & $121.0500 \rightarrow 51.2000$ & -22.0 & -36.0 & -21.0 & 20.0 \\
\hline \multirow{2}{*}{ Caffeic Acid } & \multirow{2}{*}{13.714} & \multirow{2}{*}{$\mathrm{C}_{9} \mathrm{H}_{8} \mathrm{O}_{4}$} & \multirow{2}{*}[\mathrm{M}-\mathrm{H}]{$^{-}$} & $179.1500 \rightarrow 135.0000$ & 12.0 & 18.0 & 25.0 & 20.0 \\
\hline & & & & $179.1500 \rightarrow 134.0000$ & 12.0 & 25.0 & 24.0 & 20.0 \\
\hline \multirow{3}{*}{ Sinapic acid } & \multirow{3}{*}{14.361} & \multirow{3}{*}{$\mathrm{C}_{11} \mathrm{H}_{12} \mathrm{O}_{5}$} & \multirow{3}{*}[\mathrm{M}+\mathrm{H}]{$^{+}$} & $224.9000 \rightarrow 207.1000$ & -15.0 & -10.0 & -16.0 & 20.0 \\
\hline & & & & $224.9000 \rightarrow 161.0000$ & -10.0 & -10.0 & -18.0 & 20.0 \\
\hline & & & & $224.9000 \rightarrow 91.1500$ & -15.0 & -27.0 & -21.0 & 20.0 \\
\hline \multirow{3}{*}{$\begin{array}{l}\text { trans-Isoferulic } \\
\text { acid }\end{array}$} & \multirow{3}{*}{14.728} & \multirow{3}{*}{$\mathrm{C}_{10} \mathrm{H}_{10} \mathrm{O}_{4}$} & \multirow{3}{*}[\mathrm{M}+\mathrm{H}]{$^{+}$} & $194.9000 \rightarrow 177.1000$ & -13.0 & -11.0 & -13.0 & 20.0 \\
\hline & & & & $194.9000 \rightarrow 131.0000$ & -13.0 & -11.0 & -15.0 & 20.0 \\
\hline & & & & $194.9000 \rightarrow 89.1500$ & -13.0 & -32.0 & -19.0 & 20.0 \\
\hline \multirow{2}{*}{ trans-Ferulic Acid } & \multirow{2}{*}{14.733} & \multirow{2}{*}{$\mathrm{C}_{10} \mathrm{H}_{10} \mathrm{O}_{4}$} & \multirow{2}{*}[\mathrm{M}-\mathrm{H}]{$^{-}$} & $193.0500 \rightarrow 134.0000$ & 10.0 & 18.0 & 23.0 & 20.0 \\
\hline & & & & $193.0500 \rightarrow 178.0500$ & 10.0 & 15.0 & 15.0 & 20.0 \\
\hline \multirow{2}{*}{$\begin{array}{c}\text { para-Coumaric } \\
\text { acid }\end{array}$} & \multirow{2}{*}{14.818} & \multirow{2}{*}{$\mathrm{C}_{9} \mathrm{H}_{8} \mathrm{O}_{3}$} & \multirow{2}{*}[\mathrm{M}-\mathrm{H}]{$^{-}$} & $163.0500 \rightarrow 119.0500$ & 11.0 & 16.0 & 21.0 & 20.0 \\
\hline & & & & $163.0500 \rightarrow 93.0500$ & 12.0 & 31.0 & 17.0 & 20.0 \\
\hline \multirow{2}{*}{$\begin{array}{l}\text { 2-Methoxy-4- } \\
\text { vinylphenol }\end{array}$} & \multirow{2}{*}{17.972} & \multirow{2}{*}{$\mathrm{C}_{9} \mathrm{H}_{10} \mathrm{O}_{2}$} & \multirow{2}{*}[\mathrm{M}+\mathrm{H}]{$^{+}$} & $150.8000 \rightarrow 91.2500$ & -10.0 & -22.0 & -19.0 & 20.0 \\
\hline & & & & $150.8000 \rightarrow 65.2000$ & -25.0 & -32.0 & -28.0 & 20.0 \\
\hline \multirow{3}{*}{$\begin{array}{l}\text { trans-Cinnamic } \\
\text { acid }\end{array}$} & \multirow{3}{*}{18.600} & \multirow{3}{*}{$\mathrm{C}_{9} \mathrm{H}_{8} \mathrm{O}_{2}$} & \multirow{3}{*}[\mathrm{M}+\mathrm{NH}4]{$^{+}$} & $165.0000 \rightarrow 101.2000$ & -12.0 & -12.0 & -20.0 & 20.0 \\
\hline & & & & $165.0000 \rightarrow 69.2000$ & -12.0 & -23.0 & -29.0 & 20.0 \\
\hline & & & & $165.0000 \rightarrow 133.2500$ & -11.0 & -10.0 & -15.0 & 20.0 \\
\hline
\end{tabular}

The first MRM transitions found were used for qualitative analysis, while the second or third for quantitative. 


\subsection{Preparation of the Lipid Fraction by Alkaline-Assisted Hydrolysis and Liquid-Liquid Extraction}

For the hydrolysis of bran matrix and release of bound forms of fatty acids, the $10 \%(w / v) \mathrm{KOH}$ dissolved in 80\% MeOH (MeOH:DWW ratio 80:20 v/v) was used. In excess of $\mathrm{MeOH}$, this method allows the process of hydrolysis and release of fatty acids to be done more efficiently. Triplicate samples of $5 \pm$ $0.1 \mathrm{~g}$ of ground bran were weighed in $25 \mathrm{ml}$ reagent bottles with screw caps. For the hydrolysis $20 \mathrm{~mL}$ of prepared methanolic $\mathrm{KOH}$ was added to bran and the mixture was subjected to incubation in a water bath "TW8" (Julabo ${ }^{\circledR}$, Saalbach-Hinterglemm, Germany) at $65^{\circ} \mathrm{C}$ for $3 \mathrm{~h}$. After hydrolysis the release of fatty acids from the salt form was done by shifting the $\mathrm{pH}$ of the medium from alkaline to acidic by adding $6 \mathrm{M} \mathrm{HCl}$ until the $\mathrm{pH}$ was 2.0. The extraction of the lipophilic fraction was accomplished by liquid-liquid phase separation using $n$-hexane as a solvent. $10 \mathrm{~mL}$ of $n$-hexane was added to the prepared hydrolysates (total $15 \mathrm{~mL}$ ), followed by vortex-mixing for $1 \mathrm{~min}$ and separation of the layers by centrifugation at $4500 \mathrm{rpm}(3169 \times \mathrm{g})$ for $10 \mathrm{~min}$ in a "Sigma, 2-16KC" centrifuge (Osterode near Harz, Germany). The top $n$-hexane layer was separated and collected. The extraction procedure was repeated three times. The resulting lipophilic fraction $(30 \mathrm{~mL})$ was further evaporated using a "Laborota 4002" rotary evaporator (Heidolph, Swabia, Germany) at $65^{\circ} \mathrm{C}$ and the dry fraction was then re-dissolved in 2 $\mathrm{mL}$ of pyridine, filtered through a polytetrafluoroethylene hydrophobic membrane filter with a pore size $0.45 \mu \mathrm{m}$ (VWR ${ }^{\mathrm{TM}}$, International, $\mathrm{GmbH}$.) The filtrates were quantitatively transferred to $22 \mathrm{~mL}$ glass headspace chromatography bottles for further chromatographic work and analysis.

\subsection{Preparation of Fatty Acids for GC/MS Analysis}

TMPAH reagent was used as methylation agent of the polyfunctional groups to obtain volatile fatty acid derivatives. The methylation procedure was performed according to the protocol described in the America Society for Testing and Materials [20]. Briefly, $5 \mu \mathrm{L}$ aliquot of lipid fraction was taken from the separated lipophilic fraction and $5 \mu \mathrm{L}$ of $1 \%$ phenolphthalein indicator $\left(\mathrm{C}_{20} \mathrm{H}_{14} \mathrm{O}_{4}\right.$ : $\mathrm{EtOH}$ ratio 1:99 w/v), 6 $\mu \mathrm{L}$ of $0.5 \mathrm{M}$ TMPAH reagent and $930 \mu \mathrm{L}$ of methanol:diethyl ether $\left(\mathrm{MeOH}: \mathrm{Et}_{2} \mathrm{O}\right.$ ratio 50:50 v/v) were added to the vial. The resulting pink mixture was vortex-mixing for $1 \mathrm{~min}$ and kept in a GC oven at 60 ${ }^{\circ} \mathrm{C}$ for $30 \mathrm{~min}$. The mixture was cooled to room temperature and further used for FAMEs analysis on GC/MS system. Quantification of compounds was done using a standard solution of $\mathrm{C}_{4}-\mathrm{C}_{24}$ FAMEs, building calibration curves for each compound individually.

\subsection{The GC Conditions for FAMEs Analysis}

The analysis of fatty acid methyl esters (FAMEs) was carried out on a "Clarus 600" system PerkinElmer, Inc. (Waltham, MA, USA) equipped with a quadrupole analyzer "Clarus $600 \mathrm{C}^{\prime}$ massselective detector (Waltham, MA, USA). The chromatographic separation of FAMEs was done using "Trace ${ }^{\mathrm{TM}}$ TR-FAME" (Thermo Fisher Scientific, Waltham, MA USA) column with a cyanopropylphenylbased stationary phase $(50 \mathrm{~m} \times 0.22 \mathrm{~mm}$, sorbent thickness $-0.25 \mu \mathrm{m})$ specifically designed for the separation of cis- and trans- isomers of FAMEs (Supplementary Figure S1). The injector temperature has been set to $+280{ }^{\circ} \mathrm{C}$; automatic injection using an autosampler, injection volume $0.5 \mu \mathrm{L}$; split ration 4:1. The initial oven temperature was maintained at $70{ }^{\circ} \mathrm{C}$ for $2 \mathrm{~min}$, then raised to $150{ }^{\circ} \mathrm{C}$ (rate of $20^{\circ} \mathrm{C} \mathrm{min}^{-1}$ ), then increased to $250{ }^{\circ} \mathrm{C}$ (rate of $4{ }^{\circ} \mathrm{C} \mathrm{min}-1$ ). Helium (ultra-high purity 5.0 grade $-99.999 \%$ ) was used as a carrier gas at the constant flow rate of $1.0 \mathrm{~min}$ with the split ratio n:1. The total separation time was $31.00 \mathrm{~min}$. The analysis was performed in triplicate.

\subsection{The MS Conditions for FAMEs Detection}

Detector mode: Electron impact ionization was at $70 \mathrm{eV}$; ion source temperature: $+230{ }^{\circ} \mathrm{C}$; inlet temperature was +280; capture time starting from 6.5 min $\left(1.7 \mathrm{scan} \mathrm{s}^{-1}\right)$; ion multiplier: $240 \mathrm{~V}$; and ion $\mathrm{m} / \mathrm{z}$ interval: 41-500 atom mass units (AMU) for FAMEs. 


\subsection{Statistical Analysis}

The results obtained are shown as means \pm standard deviation of the mean from three replicates $(n=$ $3)$. The $p$-value $<0.05$ was used to denote significant differences between mean values determined using one-way analysis of variance (ANOVA) and the Duncan's multiple range test done using the assistance of IBM ${ }^{\circledR}$ SPSS $^{\circledR}$ Statistics program 20.0 (SPSS Inc., Chicago, IL, USA).

\section{Results and Discussion}

\subsection{Release of FA from Bran Using Enzyme-Assisted Hydrolysis}

In the field of phytochemical research, the occurrence of ferulic acid (FA) and its isomers represents an emerging topic. Much attention has been paid to this issue, chiefly regarding the health benefits of various grain-derived products and by-products containing HCMs [21]. In nature, FA appears as cis- and trans- forms of two stereoisomers which present mainly in covalently bound forms within cell wall components [22]. According to Palafox-Carlos et al. inference [23], the dietary fiber-bound complexes form groups of compounds called non-extractable polyphenols. The release of these compounds from plant matrix varies depending on the complexity of the structure as well the ways in which compounds and dietary fiber are interlinked [5]. Since nearly $97 \%$ of FA in cereal bran is bound with various macromolecules forming cross-links, the efficient release/ extraction of this compound presents a challenge. The alkaline hydrolysis of complex agro-industrial by-products was reported as an effective tool for the extraction of FA and other HCMs. However, concerning environmental pollution matters and governmental intentions outlined in the EC Directive 2010/75/EU [24], aiming to reduce the negative impact of industrial toxic emissions on ecosystems creates an additional demand for developing green technologies for the production of chemicals from renewable sources. More recently, Martín-Diana et al. [7] introduced a novel strategy to produce ingredients rich in FA by means of EH done by multi-enzyme complex Ultraflo XL of thermally and pressure pretreated wheat bran. Following the process developed, $100 \mathrm{~g}$ of processed wheat bran could deliver up to $248.94 \mathrm{mg}$ of FA. Based on the HPLC-ESI-QTOF/MS approach the authors managed to detect the presence of both cis- and trans- FA isomers in their hydrolysates.

To establish the ability of lignocellulose-degrading enzymes to release bound FA forms from bran matrices, incl., rye, wheat, and oat, the $\mathrm{EH}$ with a single process step was used in this study. In this set of experiments, bran samples underwent 12 to $72 \mathrm{~h} \mathrm{EH}$ solely by non-starch polysaccharide degrading enzymes (N-SPs), i.e., Viscozyme L, Celluclast $1.5 \mathrm{~L}$, and Viscoferm. The highest yield of $t$-FA in all cases of enzymes applied was obtained from rye and wheat bran after $48 \mathrm{~h}$ of $\mathrm{EH}$, except for wheat bran and Viscozyme L, where the highest yield was acquired already after $24 \mathrm{~h}$ (Figure 2A and 2B). 

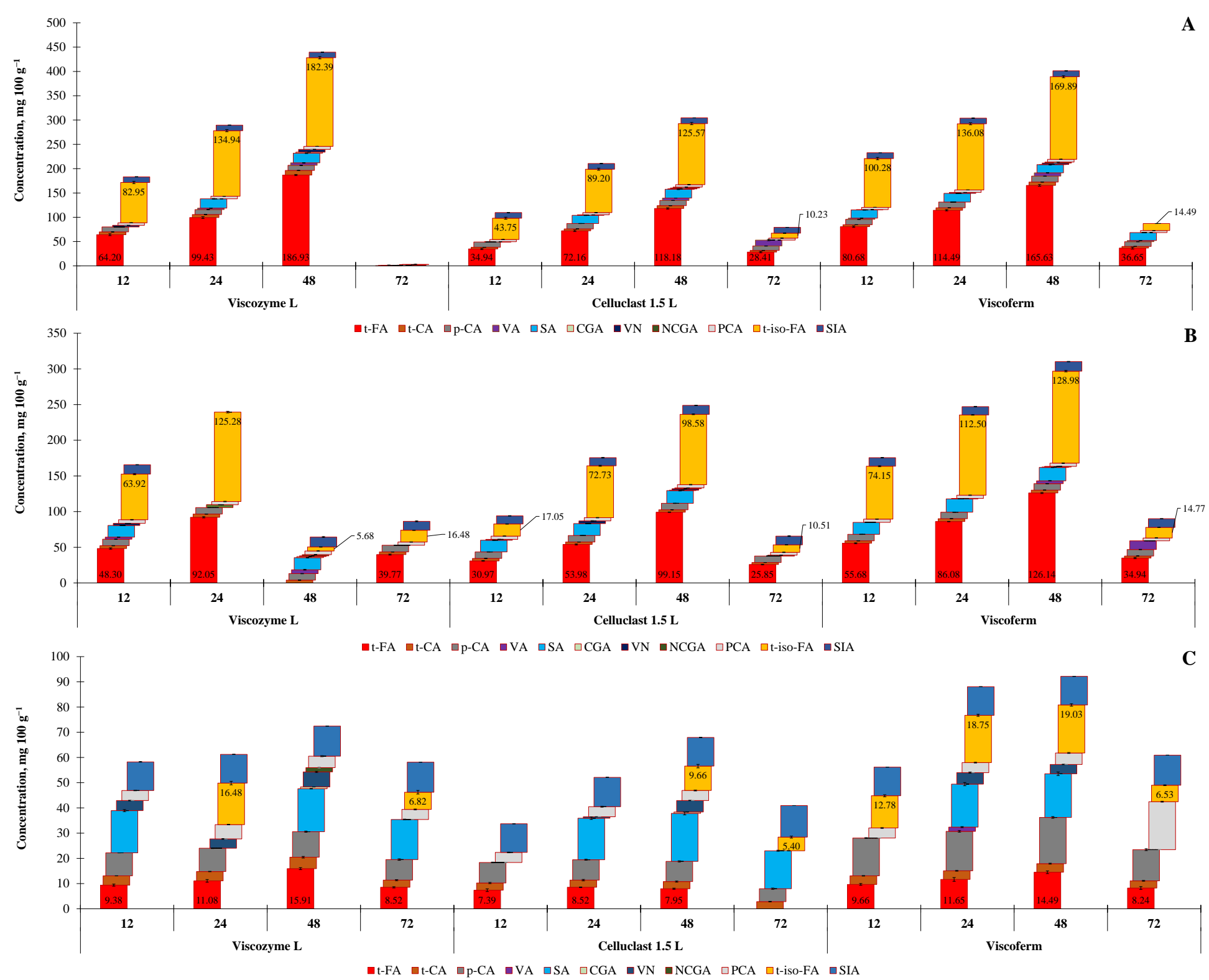

Figure 2. The release of FA and other HCMs using enzymatic hydrolysis of rye (A), wheat (B), and oat (C) bran applying three multi-enzyme complexes, i.e., Viscozyme L, Celluclast $1.5 \mathrm{~L}$, and Viscoferm, $\mathrm{mg} 100 \mathrm{~g}^{-1} \mathrm{DW}$. Note: Values are means \pm SD values of triplicates $(\mathrm{n}=3)$. 
However, upon EH, a significant loss of $t$-FA by $16.5-37.2 \%$ and $18.7-99.4 \%$ was observed for rye and wheat bran, respectively, indicating further degradation process caused by thermal decarboxylation of HCMs as revealed by Ohra-Aho et al. [25]. This observation is reinforced by the presence of 2-methoxy4-vinylphenol (4-VG) (4-vinyl guaiacol) and 4-allyl-2-methoxyphenol (eugenol), the degradation products of FA and Klason lignin, respectively (Figure 3A and 3B).
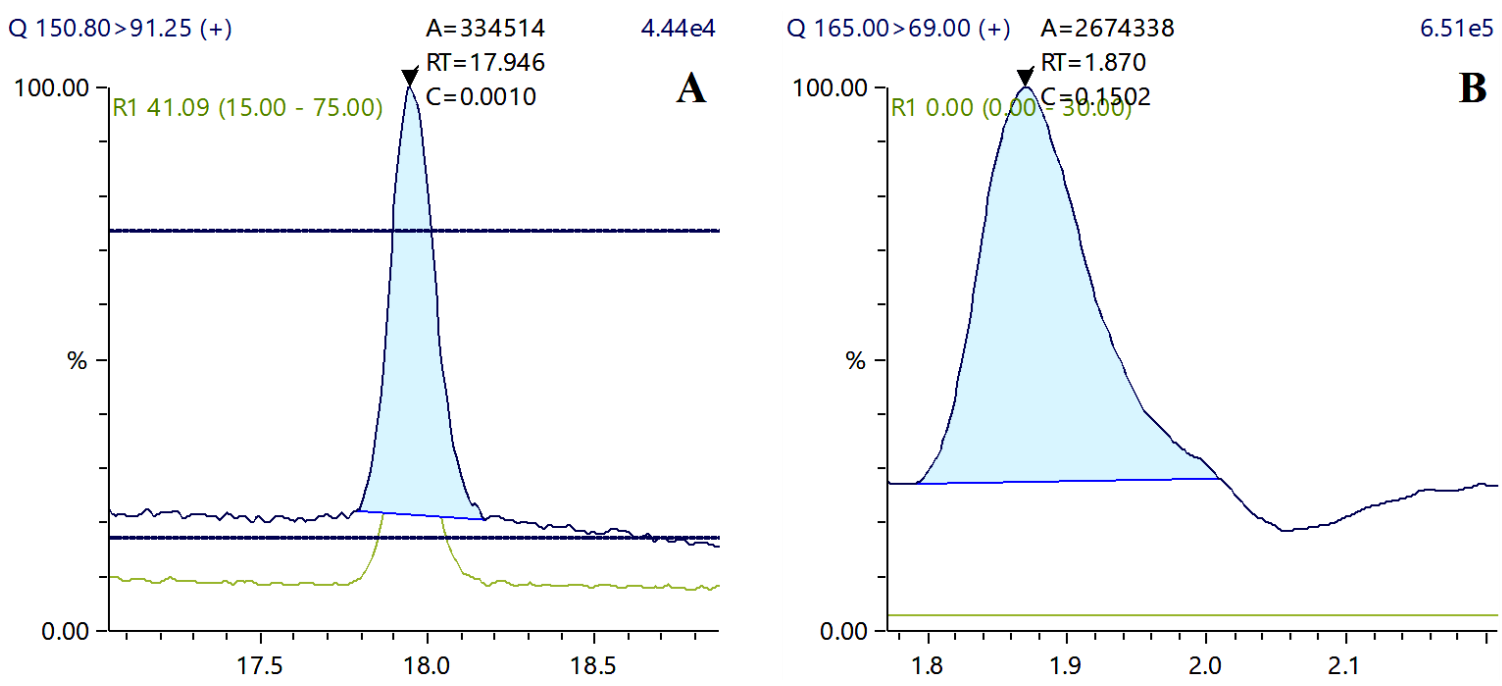

Figure 3. Extracted ion chromatograms (EIC) plotted for the degradation products of 2-methoxy-4vinylphenol (A) and 4-allyl-2-methoxyphenos (B).

Among the hydrolytic enzymes examined, the advantage of Viscozyme $L$ above other enzymes was noticed during the processing of rye bran. This observation is also established by Mahmoudi et al. [26], working with the enzyme-assisted extraction of bioactives from sweet basil by-products. However, conducting EH of wheat bran with multi-enzyme complex Viscoferm, up to 1.4-fold higher yield of $t$-FA was reached than during EH with Viscozyme L. It is worth noting, though, that the selective MRM-MSbased approach revealed no presence of $t$-FA in wheat bran hydrolysates that underwent $\mathrm{EH}$ with Viscozyme $\mathrm{L}$ for $48 \mathrm{~h}$. The absence of $t$-FA in hydrolysates can be explained by the ability of trans- isomer of FA to be isomerized to cis- form under UV irradiation that, perhaps, took place during the next $24 \mathrm{~h}$ of EH [27]. Notably, a smaller release of $t$-FA was found in oat bran (Figure 2C), but, along with $t$-FA, an equivalent yield of other HCMs was detected in obtained hydrolysates. The concentration of $t$-FA was almost 11.7-fold and 7.9-fold lower than that released from rye and wheat bran, respectively. A similar amount of $t$-FA released after alkaline-assisted hydrolysis of oat bran has been reported by [28].

The second prevalent HCM isolated from bran hydrolysates and further successfully quantified was

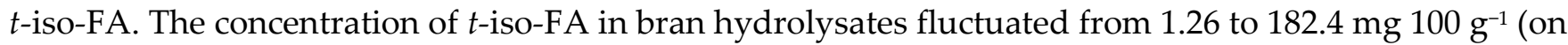
a dry weight basis) depending on the enzyme and the duration of $\mathrm{EH}$ used. Among the 3 hydrolytic enzymes screened, the highest yield of $t$-iso-FA, similarly to $t$-FA, was obtained in rye bran samples subjected to $48 \mathrm{~h}$ EH with multi-enzyme complex Viscozyme L. Considerably smaller release of $t$-iso-FA from rye bran matrix was observed after $48 \mathrm{~h} \mathrm{EH}$ with Viscoferm, though the amount was 1.3-fold higher than the Celluclast 1.5 L does. The presence of $t$-iso-FA in the grains and grain-derived fractions of such crops as wheat, oats, barley, corn, red rice, and rye has already been confirmed by [29-31], indicating that rye contains the highest amount, but the ratio of free to bound $t$-iso-FA is 10:90. However, the amounts described herein are 4.4- and 28.4-fold higher than that previously reported for wheat and oat bran, respectively.

The most available literature on clinical trials refers to $t$-iso-FA derived from Cimicifugae rhizoma, a medical herb with multiple well-documented health-promoting benefits [32,33], although little attention has been given to other sources of $t$-iso-FA. However, despite the beneficial health effects outlined in the report of $\mathrm{Li}$ and $\mathrm{Yu}$ [34], there are little generalized information about the exact concentration of $t$-iso- 
FA. It was hypothesized that the grain-derived hydrolysates discussed herein may have the same beneficial health effects, and could be used as a remedy in the prevention and treatment of various ailments which is also supported by [31].

The SA is the third HCM the presence of which was confirmed in all bran hydrolysates obtained by selected enzymes. The advantage of using Viscoferm over other enzymes was noticed during the processing of wheat bran, since this preparation was able to deliver up to $18.75 \mathrm{mg} 100 \mathrm{~g}^{-1}$ of SA within 24 and $48 \mathrm{~h}$ of EH. The yield of SA in this study is analogous to that obtained by alkaline-assisted hydrolysis of whole wheat grains [35]. The authors highlighted that SA after FA and dimeric FA is the third most prevalent HCM released from whole wheat grains. However, contradicting results were observed in case of rye bran, where the yield of SA was highest in the sample which underwent EH with Viscozyme L for 24 and $48 \mathrm{~h}$. This time, a comparable amount of SA was found in oat bran hydrolysates after EH with Celluclast $1.5 \mathrm{~L}$, and the highest yield was observed after $48 \mathrm{~h}$ of $\mathrm{EH}$. The EH of oat bran with Viscoferm and Viscozyme L regardless of EH duration delivered a lower yield of SA. Similar to this study, the advantage of a developed biorefining process aimed at releasing SA from mustard bran has been demonstrated in the report of Achinivu et al. [36], highlighting better release of SA than that of alkali processed bran.

The small-scale process revealed each enzyme contributed differently to the release of HCMs from bran matrix due to its specificity and activity, though among the enzymes tested, the superiority of multienzyme complex Viscozyme L must be highlighted. Overall, a gentler approach ensured up to $215.7 \%$ release of the total alkali-extractable FA from rye bran, while 79.5 and $60.3 \%$ release can be achieved from wheat and oat, respectively.

\subsection{Release of FA from Bran Using Enzyme-Assisted Hydrolysis of 10- and 30-fold Scale-Up Process}

The EH at high solids loadings is another important key to the scale-up process for the release of FA from complex matrices. Due to the presence of higher free sugars and other bioactives that can act as inhibitors and therefore interfere with the release of target compounds, the process of scaling is necessary to establish the applicability of developed technology. The increase in solids loading could significantly reduce the efficiency of mass and heat transference, influence the degree of substrate homogeneity, limit the formation of the enzyme-substrate complex by restricting the access of the enzyme to available substrate resulting in lower solubilization of cellulose, hemicellulose, $\beta$-glucan, and other non-soluble dietary fiber. There have hitherto been developed various pretreatment strategies regarding the productivity, yield, and the number of steps to enhance the hydrolysis of lignocellulose materials. Over the last years, pilot-scale operational conditions have been proposed for alkaline [37,38], hydrothermal [39], and ultra-fast hydrolysis by supercritical $\mathrm{CO}_{2}$ pretreatments. More recently, Ferri et al. [6] demonstrated a robust and eco-friendly three-step biorefinery solution for the efficient release of FA. The proposed technology seems to be valid for the industrial-scale production of FA. So far, however, there is limited information on large-scale EH of rye bran, especially at high solids loading, so the current experiment will be focused on scaling-up the $\mathrm{EH}$ process accomplished by three hydrolytic enzymes in a single step.

A 10- and 30-fold scale-up was carried out using a bioreactor using the parameters developed for small-scale FA release. The release of FA and other HCMs was analyzed after $48 \mathrm{~h}$ of EH, since reduction in the content of both FA isomers was observed for wheat bran, while no significant changes in the release of HCMs were taken place for rye bran during further $24 \mathrm{~h}$ of small-scale EH process (Figure 4 ). Besides, additional energy input would make this process not economically feasible, resulting in a higher price of the final product. 


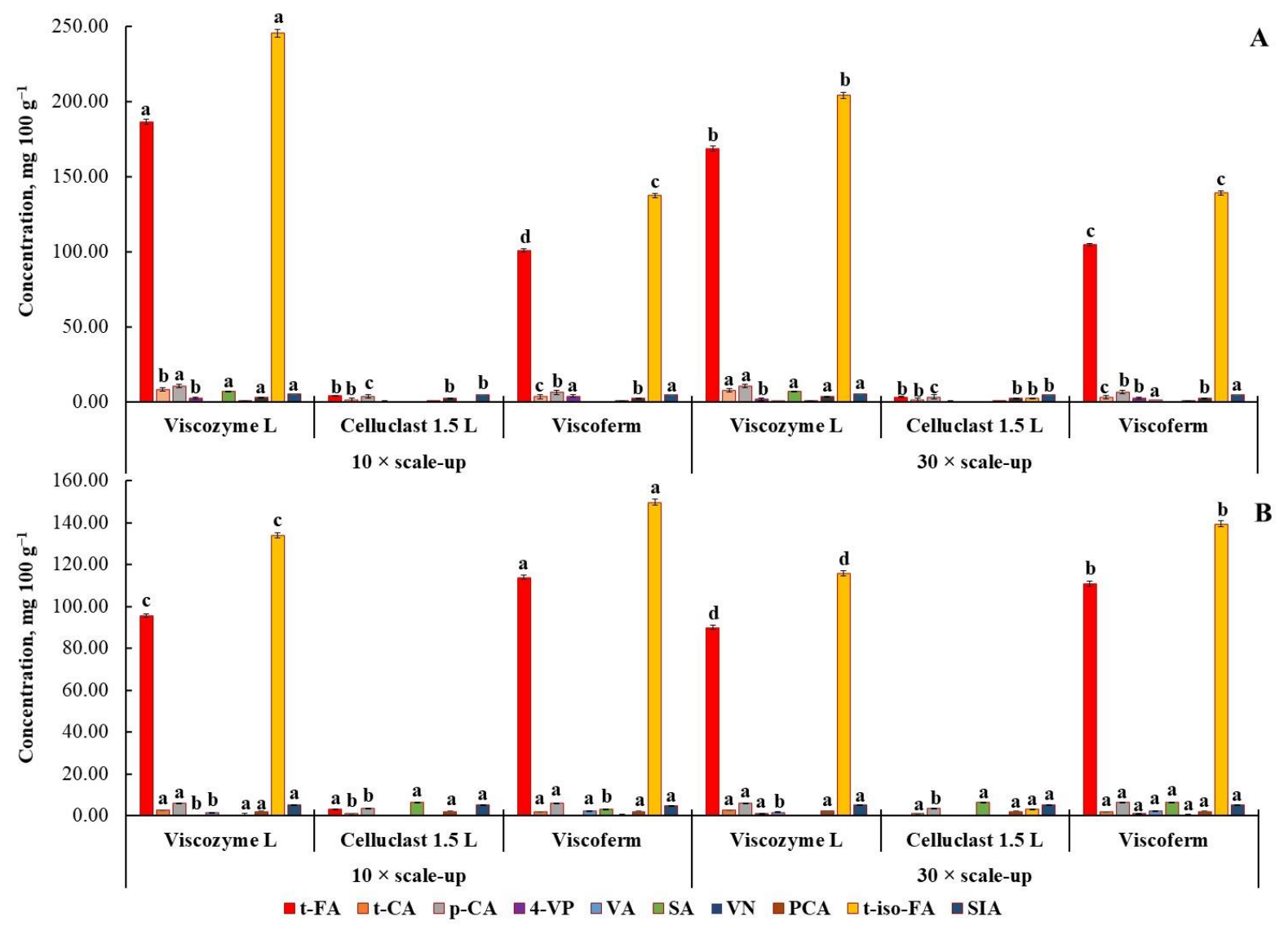

Figure 4. The release of FA and other HCMs after enzymatic hydrolysis of rye (A) and wheat (B) bran for $48 \mathrm{~h}$ with three multi-enzyme complexes, i.e., Viscozyme L, Celluclast 1.5 L, and Viscoferm, mg 100 $\mathrm{g}^{-1} \mathrm{DW}$. Note: The process was done 10 - and 30 -fold scaled up process. Values are means $\pm \mathrm{SD}$ values of triplicates $(n=3)$. Means within the same HCMs with different superscript letters $(a, b, c, d)$ are significantly different at $p<0.05$.

A 10- and 30-fold scale-up process confirmed the applicability of $\mathrm{EH}$ as a bioprocessing type valid for industrial-scale FA production. Similarly, as in small-scale, the advantage of Viscozyme L over other hydrolytic enzymes has been proved scaling up process (Figure 4A).

Chromatographic separation of rye-bran derived HCMs is depicted in Figure 5. 

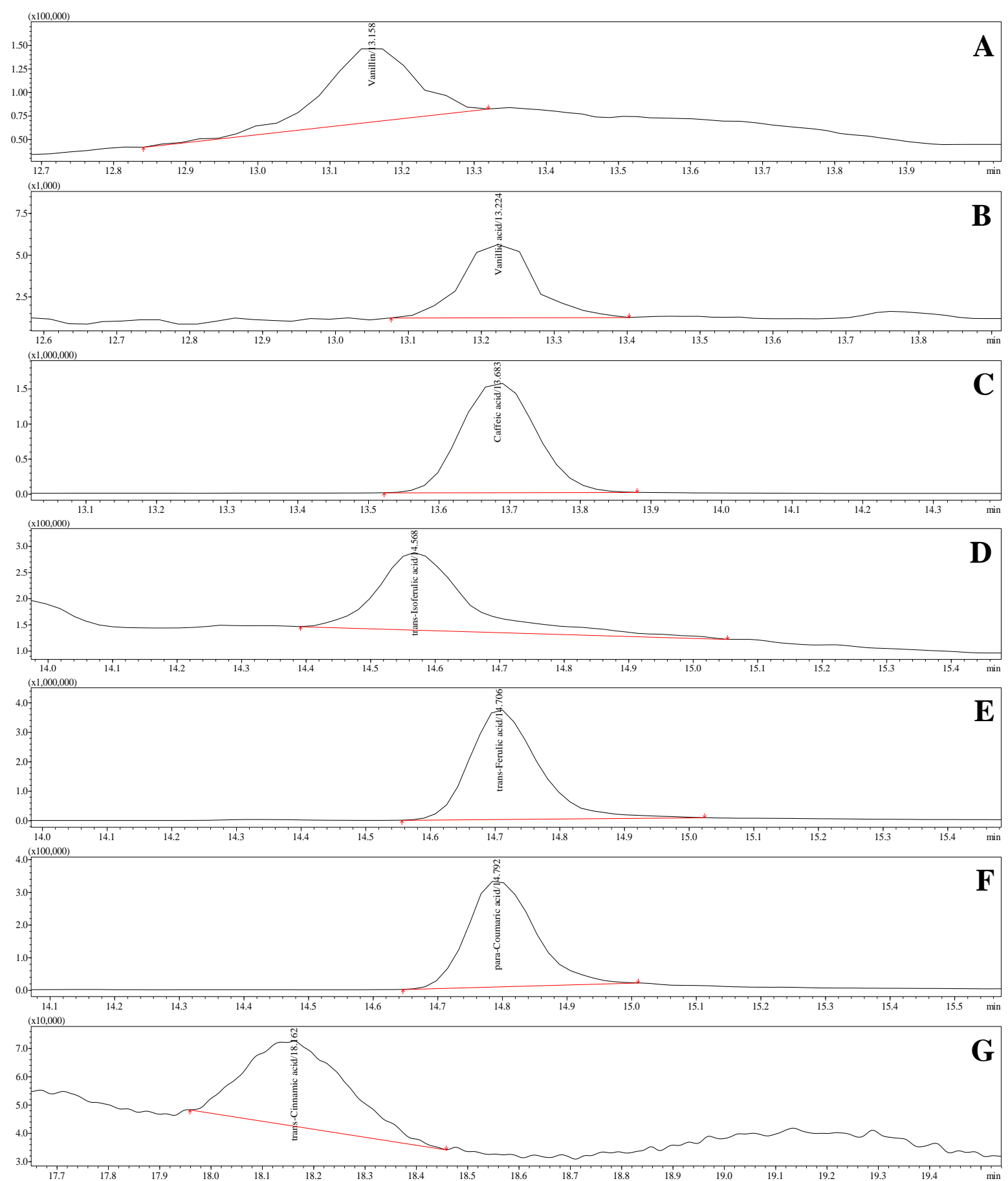

Figure 5. Representative profile of HCMs detected in rye bran hydrolysates: VN (A), VA (B), CA (C), tiso-FA (D), $t$-FA (E), $p$-CA (F), and $t$-CA (G) using a HPLC-ESI-QqQ-MS operating with the multiple reaction monitoring mode.

At 10 - and 30-fold scales, up to 431.9 and $372.6 \mathrm{mg}$ of FA (sum of $t$-FA and $t$-iso-FA) can be produced from $100 \mathrm{~g}$ of rye bran by the way of $\mathrm{EH}$, respectively. However, as can be seen, the highest concentration of FA was reached at the 10 -fold scaled experiment. It is worth noting the amount of FA released at the bioreactor scale was found to be significantly higher than was observed at smaller scales. A plausible explanation for getting a better release of FA was provided by Ferri et al. [6], who posits the bioreactor scale conditions improved $\mathrm{EH}$ performance as a result of controlled $\mathrm{pH}$ and continuous agitation of the slurry. All this made it attainable to reach a more homogeneous enzymatic reaction and hydrolysis efficiency. 
As with small-scale $\mathrm{EH}$, better release of FA from wheat bran was observed during $\mathrm{EH}$ with Viscoferm (Figure 4B). The produced amount of FA in both 10- and 30-fold scaled-up experiments was significantly higher than observed for other enzymes. Using proposed conditions $100 \mathrm{~g}$ of $\mathrm{EH}$ wheat bran could deliver up to 263.6 and $250.2 \mathrm{mg}$ of FA, respectively. As seen, significantly higher yield of $t$-FA and $t$-iso-FA was found for the 10-fold scale-up experiment.

Due to gentler hydrolysis conditions, the scaled-up EH process of rye and wheat bran with Viscozyme and Viscoferm demonstrated up to 217.6 and $91.2 \%$ release of the total alkali-extractable FA (sum of $t$-FA and $t$-iso-FA) from rye and wheat bran, respectively.

\subsection{Release of FA from Bran Using SFE-CO2 Extraction}

The interactions between intracellular phytochemicals and cell walls have a significant influence on the extractability of compounds of interest from complex plant matrices [5], incl. whole grains and their derived fractions. Recently, a couple dozen extractants were investigated and proposed for the industrial-scale production of dietary polyphenols, generally favoring such solvents or their blends as acetone [40], methanol [41], diethyl ether, and ethyl acetate [42], even though they may be harmful to operators and environment. Among the extraction methods documented, superior extractability of phytochemicals from complex matrices was reported for SFE [43]. Due to the GRAS status assigned and relatively low costs, $\mathrm{CO}_{2}$ is the most widely used supercritical fluid suitable for both research purposes and industrial scales. Since neat supercritical fluid $\mathrm{CO}_{2}$ has dissolving propertied close to hexane that is recognized as an excellent solvent for extracting non-polar compounds, the addition of co-solvent could enhance the solubilizing properties of $\mathrm{CO}_{2}$, making it attainable to recover more polar molecules. Due to the process taking place in a closed loop, the online extraction, separation, and analysis of HCMs using SFE-CO $\mathrm{CO}_{2}$ SFC to MS-TQ make it attainable to reduce both qualitative and quantitative losses of analytes during analytical work.

For comparative purposes of the EH efficiency, the SFE- $\mathrm{CO}_{2}$ extraction coupled to SFC-MS-TQ was applied in this experiment. Since such extraction parameters or their interactions as temperature, pressure, co-solvent concentration, and mode (static and dynamic) could influence the yield compounds of interest, a series of SFE-SFE operational conditions were investigated in a lab-scale Nexera UC SFESFC-LC-MS-QT apparatus (Table 3).

In the first test runs 1-4, the influence of extraction temperature over the range of $40-60{ }^{\circ} \mathrm{C}$ was investigated, while pressure, co-solvent concentration (modifier), and extraction parameters were kept constant at $10 \mathrm{MPa}, 10 \% \mathrm{EtOH}$, and 3:3 min, respectively (Figure 6). The selected temperature range was based on a previous report [44]. As expected, the yield of FA and other HCMs increased with the increase in extraction temperature, while, rising the temperature over $50{ }^{\circ} \mathrm{C}$, the amount of $t$-FA decreased significantly $(p<0.05)$, and the observed value was even lower than that obtained at $45^{\circ} \mathrm{C}$ (Figure $6 \mathrm{~A}$ ). The results are consistent with those of [45,46], indicating that the vast majority of phenolics and antioxidants present in grape seeds and cranberry bush berries and pomace were extracted using a temperature range of $44-46^{\circ} \mathrm{C}$. A plausible explanation for getting better release of FA has been given by Ameer et al. [43], pointing out that elevated temperature after plant matrix is wetted allows reducing surface tension and rising solvent cavitation that accelerate dissolution of analyte in the solvent.

It is worth noting the presence of $t$-iso-FA was found only when rye bran samples were subjected to extraction at $50{ }^{\circ} \mathrm{C}$ temperature. Therefore, an extraction temperature of $50{ }^{\circ} \mathrm{C}$ was used for subsequent extractions. The third prevalent compound extracted from rye bran samples by means of $\mathrm{SFE}-\mathrm{CO}_{2}$ was VA. The yield of this HCM fluctuated in the range of 133.2-166.4 mg $100 \mathrm{~g}^{-1}$. It should be admitted that the value of VA was found to be significantly higher than yielded during EH, indicating possible decarboxylation process of free VA caused by elevated temperature during hydrolysate autoclaving. The presence of 4-VG as the primary degradation product of VA is also confirmed by [47].

To evaluate the effect of pressure on the extractability of FA from rye bran matrix by SFE- $\mathrm{CO}_{2}$, the experiments (5-8) were carried out using extraction pressure within the range of 10-25 MPa at a constant temperature $\left(50^{\circ} \mathrm{C}\right)$, concentration of modifier $(10 \%)$, and the length of static to dynamic mode (3:3 $\left.\mathrm{min}\right)$. 
As seen (Figure 6B), the yield of $t$-FA was significantly higher when rye bran samples were subjected to 25 and $15 \mathrm{MPa}$ extraction pressures. However, when extracting at $25 \mathrm{MPa}$, the presence of $t$-iso-FA was not detected, revealing higher susceptibility of $t$-iso-FA to degradation by elevated pressure than $t$-FA. Although, when calculating the total amount of these two HCMs, the obvious advantage of using 15 $\mathrm{MPa}$ pressure among all other pressures is noticed. Considering the yield of other HCMs, it is seen that there were no significant differences in the content of CA, $p$-CA, and VN, therefore the pressure of 15 $\mathrm{MPa}$ was selected for further extractions to minimize wear of the machine parts.

To study the influence of co-solvent concentration on the extractability of FA from rye bran, the experiments in the next series of runs (9-12) were conducted. The addition of EtOH in the range of 7.5$20 \%$ along with the main supercritical $\mathrm{CO}_{2}$ extraction fluid was used in this experiment, while moderate operating conditions such as temperature $-50{ }^{\circ} \mathrm{C}$, pressure $-15 \mathrm{MPa}$, and the length of static to dynamic mode $-3: 3$ min were maintained constant (Figure 6C). Since $t$-FA and $t$-iso-FA present both methoxy and hydroxy substituents, and also to keep the $\mathrm{SFE}-\mathrm{CO}_{2}$ extraction "green", the polar EtOH has been selected as a co-solvent. The results showed that almost equal yields of $t$-FA could be reached with the addition of polar $\mathrm{EtOH}$ to the $\mathrm{CO}_{2}$ extraction fluid in the range of $7.5-10 \%$, though, the increase of the extraction solvent polarity and elevated viscosity resulted in a marked reduction of $t$-FA solubility and recovery. The yield of $t$-iso-FA in the fraction obtained with the use of $10 \% \mathrm{EtOH}$ as a co-solvent was found to be the highest. In turn, no presence of $t$-iso-FA was found in the extracts obtained with the addition of 15 and $20 \% \mathrm{EtOH}$. The results are consistent with data obtained in an earlier study [48], highlighting that, due to relatively low toxicity and potential applications of obtained extracts in food, cosmetic and pharmaceutical products this solvent has advantages over others. The total FA content was relatively higher by performing the extraction with the addition of $10 \% \mathrm{EtOH}$, therefore this concentration has been selected for subsequent extractions.

In the final set of experiments (13-17), when optimal values for temperature, pressure, and concentration of co-solvent for extracting of FA from bran matrix have been elucidated, the influence of extraction mode, i.e., static and dynamic and its length was investigated. As it turned out, the type of extraction has also a crucial role that could affect the yield of FA (Figure 6D). The lowest yield of $t$-FA was obtained when the extraction was done by $5 \mathrm{~min}$ static and $1 \mathrm{~min}$ dynamic mode, however, the amount of $t$-iso-FA in the extracts was the highest. To find a compromise between the yield of both $t$-FA and $t$-iso-FA, the extraction of HCMs was done using a $4 \mathrm{~min}$ static and $2 \mathrm{~min}$ dynamic mode. As can be seen, a $89.9 \%$ higher yield of $t$-FA has reached, while no presence of $t$-iso-FA was detected in the extracts obtained using this mode. A satisfactory yield of $t$-FA and $t$-iso-FA was reached only after shifting from 5 min static extraction mode to $5 \mathrm{~min}$ dynamic (static to dynamic ratio - 1:5). A credible explanation for getting better extractability of compounds applying longer dynamic mode has been given by Luque de Castro et al. [49], pointing out continuous exposure of analyte to the clean extraction solvent could enhance of displacement of the analyte partitioning equilibrium to the mobile phase.

To summarize, the introduced SFE-SFC approach is another eco-friendly alternative suitable for industrial-scale production of FA. The extractability of FA (sum of $t$-FA and $t$-iso-FA) by means of $\mathrm{CO}_{2}$ and $10 \% \mathrm{EtOH}$ as a co-solvent, $15 \mathrm{MPa}$ pressure, $50{ }^{\circ} \mathrm{C}$ temperature, and the length of the static $1 \mathrm{~min}$ and dynamic mode 5 min delivered an increase of obtained FA by $164.0 \%$ in rye, $69.9 \%$ in wheat and $329.9 \%$ in oat bran in comparison to FA obtained after alkaline-assisted hydrolysis (Figure 6E). 

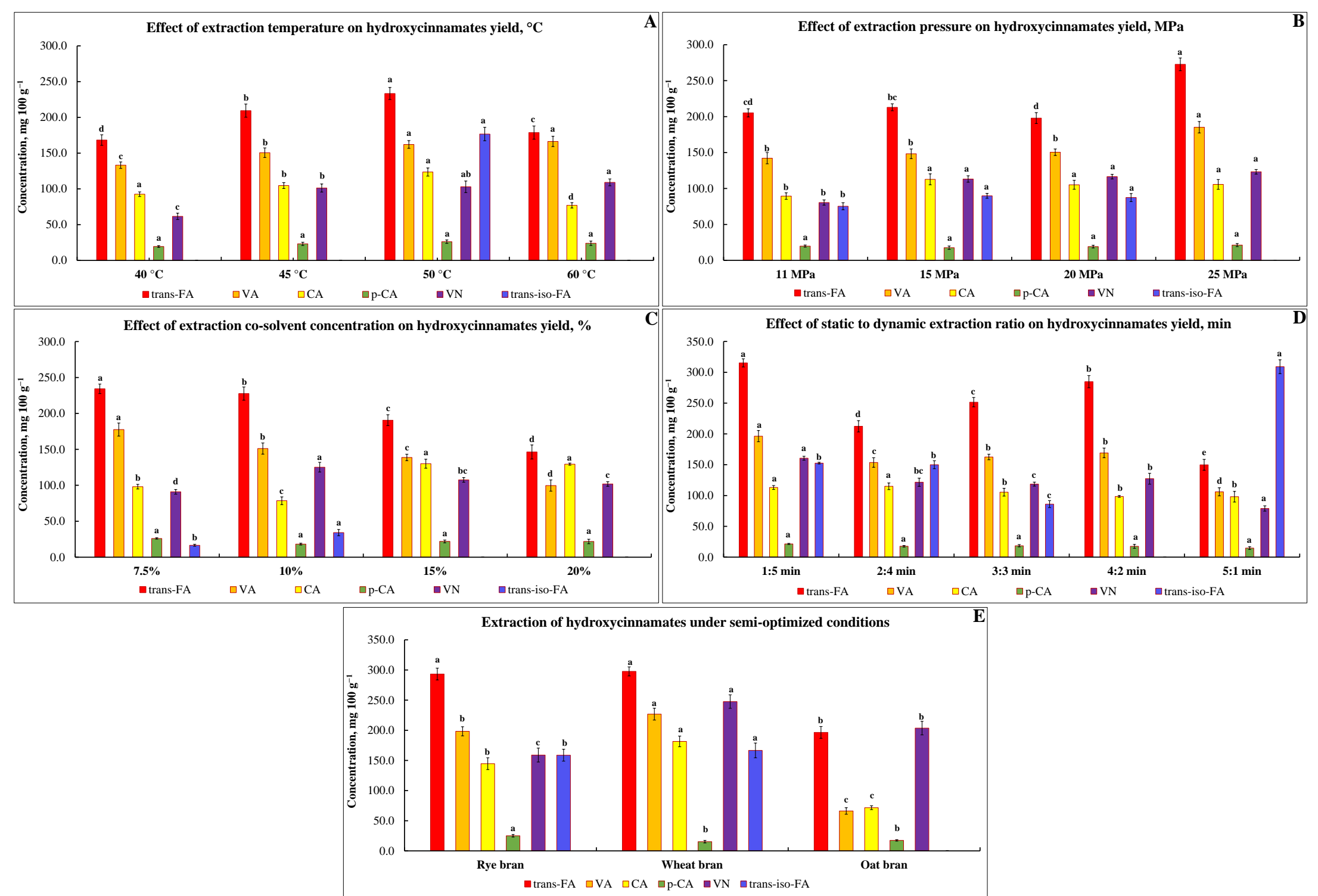

Figure 6. The release, isolation, and analysis of rye bran derived HCMs using variable (A, B, C, D) and semi-optimized SFE-CO 2 extraction conditions (E) for extraction of HCMs from bran samples, $\mathrm{mg} 100 \mathrm{~g} \mathrm{~g}^{-1} \mathrm{DW}$. Note: Values are means \pm SD values of triplicates $(n=3)$. Means within the same HCM with different superscript letters $(\mathrm{a}, \mathrm{b}, \mathrm{c}$, and d) are significantly different at $p<0.05$. 


\subsection{Release of Mono- and Disaccharides from Bran Using Enzyme-Assisted Hydrolysis}

According to Novozymes ${ }^{\circledR}$, hydrolytic enzymes selected in this study contain a wide range of carbohydrases, i.e., xylanases, cellulases, arabanases, glucanase, and hemicellulose where the end products of synergistic action could be glucose, arabinose, mannose, galactose, and xylose. It has been demonstrated that FA both in grains and grain-derived fractions is presented in covalently cross-linked form with arabinofuranosidase residues in arabinoxylans, while continuous $\mathrm{EH}$ with lignocellulosedegrading enzymes results in solubilization of water-insoluble and depolymerization of water-soluble arabinoxylans with the simultaneous release of FA [5]. This statement has been reinforced by Shin et al. [50], revealing a strong correlation between the release of FA and the yield of reducing sugars during EH of corn fiber.

Previous experiments revealed the ability of selected hydrolytic enzymes to release bound FA forms from rye, wheat, and oat bran matrix within a single process step of $\mathrm{EH}$. Therefore, the next experiment will be aimed at assessing the yield of mono- and disaccharides over $72 \mathrm{~h}$ of EH. A detailed profile of sugars after small-scale EH is depicted in Table 5. Glucose, xylose, arabinose, and fructose were the major products released from rye, wheat, and oat bran (Supplementary Figure S2), though the amount of sugars varied depending on the hydrolytic enzyme applied and length of $\mathrm{EH}$. The presence of galactose was also confirmed in bran hydrolysates, though further work with direct enzymes injections revealed the availability of this sugar as part of commercial enzymes preparations.

The action of $\alpha$-L-arabinofuranosidase has resulted in the cleavage of non-reducing end of terminal $\alpha$-L-arabinofuranoside residues in $\alpha$-L-arabinosides, and therefore the presence of feruloylated arabinose monomers at the initial stage of $\mathrm{EH}$ was revealed. Viscoferm displayed maximum hydrolytic performance after $12 \mathrm{~h}$ of $\mathrm{EH}$ since the highest yield of arabinose in rye bran hydrolysates made up 7.9 g $1000 \mathrm{~mL}^{-1}$. The obtained results are consistent with data by Gama et al. [51], indicating that arabinofuranosidase is more active at the initial stage of $\mathrm{EH}$ since, by the action of this enzyme, smaller xylan polysaccharides are formed that contain no side chains of arabinose residues, thereby ensuring the xylan area is more accessible to enzymes involved in splitting of xylosidic bonds with the simultaneous release of xylooligosaccharides along with xylose monomers. However, it is worth noting that at the end of $72 \mathrm{~h}$ a $28.4 \%$ decrease of this monosaccharide was noticed. A similar trend of arabinose decrease has been found in rye bran hydrolysates subjected to EH with Viscozyme L, where up to $40.6 \%$ of arabinose loss was observed after $72 \mathrm{~h}$ of EH. Opposite results were obtained during EH of wheat bran samples with Viscoferm, where up $150.5 \%$ increase of arabinose was observed at the end of $72 \mathrm{~h}$. Considerable fluctuations in this monomer content were detected during EH of wheat bran with Viscozyme L, the maximum peak of which was marked upon $48 \mathrm{~h}$ of EH. While additional $24 \mathrm{~h}$ hydrolysis resulted in a $44.4 \%$ reduction of this monomer. A credible explanation of this phenomenon has been given by Xin et al. [52], pointing out that continuation of the hydrolytic activity of $\alpha$-L-arabinofuranosidase can cause extensive loss of free arabinose.

Xylose is a sugar monomer that can be released during EH through the action of xylanolytic enzymes that are capable of depolymerizing xylosidic bonds present in the xylan backbone chain. The highest content of xylose monomers was observed after $48 \mathrm{~h}$ of EH with Viscozyme L. Up to 12.8 and $10.6 \mathrm{~g} 1000$ $\mathrm{mL}^{-1}$ of xylose was released from rye and wheat bran samples, demonstrating superior hydrolytic activity of this enzyme over other applied enzymes. Contrary results were reported by Bautista-Expósito et al. [53], demonstrating the superior xylanolytic performance of Viscoferm since the amount of xylose released was 7.4-fold higher than if using Viscozyme L.

According to Novozymes ${ }^{\circledR}$, the main activity of hydrolytic enzymes selected is being the glycosidic, in addition to arabinose and xylose content, the efficiency of hydrolysis has been estimated by measuring the amount of glucose in hydrolysates. The results of glucose content analysis show values ranging between 5.8 to $59.4 \mathrm{~g} 1000 \mathrm{~mL}^{-1}$ for rye, wheat, and oat bran hydrolysates, with oat bran having the highest content, while wheat bran the lowest. A higher amount of glucose in oat bran hydrolysates is explained by the presence of the relatively higher amount of $\beta$-glucan, which alongside to cellulose by 
the action of endo-1,4- $\beta$-D-glucanase release glucose monomers [54]. The maximum yield of glucose was released after $48 \mathrm{~h}$ of EH with Viscozyme L. The same observation has been made by Bautista-Expósito et al. [53], highlighting that Viscozyme L over 13 other commercial enzymes tested was the most efficient, able to release the highest amount glucose monomers from wheat bran polysaccharides. EH with Viscozyme L for $48 \mathrm{~h}$ has led to an up 76.5, 81.5, and 5.1\% increase in glucose content as compared to the initial level obtained after $12 \mathrm{~h}$ of rye, wheat, and oat bran EH, respectively. The highest release of glucose using Viscoferm was reached only passing $72 \mathrm{~h}$ of $\mathrm{EH}$, corresponding to 83.7 and $62.9 \%$ increase for rye and oat bran hydrolysates, respectively, while continuous $\mathrm{EH}$ of wheat bran samples during $72 \mathrm{~h}$ has failed to release higher amount of glucose. 
Table 5. The release of mono- and disaccharides during $72 \mathrm{~h}$ enzymatic hydrolysis of bran samples using three multi-enzyme complexes, i.e., Viscozyme L, Celluclast $1.5 \mathrm{~L}$, and Viscoferm, g $1000 \mathrm{~mL}^{-1}$ of bran hydrolysate.

\begin{tabular}{|c|c|c|c|c|c|c|c|c|c|c|c|c|}
\hline \multirow{2}{*}{$\begin{array}{l}\text { Enzyme } \\
\text { Time, h }\end{array}$} & \multicolumn{4}{|c|}{ Viscozyme L } & \multicolumn{4}{|c|}{ Celluclast 1.5 L } & \multicolumn{4}{|c|}{ Viscoferm } \\
\hline & 12 & 24 & 48 & 72 & 12 & 24 & 48 & 72 & 12 & 24 & 48 & 72 \\
\hline Carbo- & \multicolumn{12}{|c|}{ Rye bran } \\
\hline Xyl & $6.78 \pm 0.61$ & $9.43 \pm 0.55$ & $12.87 \pm 0.04$ & $9.67 \pm 0.05$ & $10.64 \pm 0.65$ & $12.30 \pm 0.96$ & $12.77 \pm 0.65$ & $11.11 \pm 0.41$ & $8.89 \pm 0.47$ & $9.91 \pm 0.52$ & $10.80 \pm 0.24$ & $10.87 \pm 0.65$ \\
\hline Ara & $5.32 \pm 0.52$ & $4.22 \pm 0.48$ & $5.14 \pm 0.03$ & $3.16 \pm 0.04$ & $2.52 \pm 0.08$ & $2.74 \pm 0.34$ & $2.53 \pm 0.19$ & $2.22 \pm 0.25$ & $7.98 \pm 0.14$ & $7.39 \pm 0.96$ & $4.59 \pm 0.42$ & $5.71 \pm 0.43$ \\
\hline Fru & $2.50 \pm 0.32$ & $2.97 \pm 0.33$ & $4.41 \pm 0.09$ & $1.58 \pm 0.01$ & $2.65 \pm 0.07$ & $2.91 \pm 0.05$ & $3.07 \pm 0.13$ & $2.51 \pm 0.21$ & $2.24 \pm 0.17$ & $3.06 \pm 0.45$ & $2.18 \pm 0.09$ & $2.88 \pm 0.14$ \\
\hline Glu & $22.22 \pm 0.43$ & $34.13 \pm 0.94$ & $39.88 \pm 0.85$ & $31.54 \pm 0.98$ & $11.50 \pm 0.21$ & $13.44 \pm 0.75$ & $13.27 \pm 0.87$ & $11.84 \pm 0.56$ & $10.81 \pm 0.42$ & $10.85 \pm 0.85$ & $10.75 \pm 0.12$ & $19.86 \pm 0.74$ \\
\hline Suc & $0.19 \pm 0.01$ & $0.00 \pm 0.00$ & $0.00 \pm 0.00$ & $0.00 \pm 0.00$ & $0.00 \pm 0.00$ & $0.00 \pm 0.00$ & $0.00 \pm 0.00$ & $0.00 \pm 0.00$ & $0.37 \pm 0.07$ & $0.00 \pm 0.00$ & $0.00 \pm 0.00$ & $0.00 \pm 0.00$ \\
\hline Mal & $0.83 \pm 0.09$ & $1.36 \pm 0.04$ & $1.34 \pm 0.01$ & $1.45 \pm 0.01$ & $0.57 \pm 0.02$ & $1.34 \pm 0.07$ & $1.37 \pm 0.08$ & $1.46 \pm 0.04$ & $0.50 \pm 0.09$ & $1.79 \pm 0.14$ & $1.72 \pm 0.05$ & $1.74 \pm 0.07$ \\
\hline Total & $37.84 \pm 1.98$ & $52.12 \pm 2.34$ & $63.64 \pm 1.02$ & $47.40 \pm 1.09$ & $27.88 \pm 1.03$ & $32.74 \pm 2.17$ & $33.00 \pm 1.92$ & $29.13 \pm 1.47$ & $30.79 \pm 1.36$ & $33.00 \pm 2.92$ & $30.04 \pm 0.83$ & $41.06 \pm 2.03$ \\
\hline Carbo- & \multicolumn{12}{|c|}{ Wheat bran } \\
\hline $\mathrm{Xyl}$ & $6.36 \pm 0.65$ & $8.17 \pm 0.15$ & $10.61 \pm 0.45$ & $8.90 \pm 0.64$ & $8.64 \pm 0.43$ & $10.68 \pm 0.21$ & $12.07 \pm 0.23$ & $9.47 \pm 0.23$ & $1.38 \pm 0.11$ & $8.60 \pm 0.41$ & $9.74 \pm 0.46$ & $10.28 \pm 0.55$ \\
\hline Ara & $1.89 \pm 0.15$ & $3.10 \pm 0.23$ & $5.11 \pm 0.21$ & $2.84 \pm 0.35$ & $2.11 \pm 0.21$ & $3.59 \pm 0.15$ & $4.11 \pm 0.14$ & $1.96 \pm 0.14$ & $1.98 \pm 0.08$ & $4.03 \pm 0.39$ & $4.31 \pm 0.25$ & $4.96 \pm 0.25$ \\
\hline Fru & $1.02 \pm 0.12$ & $1.89 \pm 0.09$ & $4.02 \pm 0.11$ & $1.48 \pm 0.21$ & $2.51 \pm 0.12$ & $3.44 \pm 0.23$ & $3.70 \pm 0.21$ & $2.63 \pm 0.11$ & $0.86 \pm 0.04$ & $1.85 \pm 0.15$ & $2.47 \pm 0.13$ & $2.87 \pm 0.36$ \\
\hline Glu & $13.84 \pm 0.43$ & $18.99 \pm 0.85$ & $25.12 \pm 0.13$ & $18.67 \pm 0.34$ & $5.88 \pm 0.14$ & $6.18 \pm 0.25$ & $6.74 \pm 0.28$ & $7.44 \pm 0.32$ & $17.26 \pm 0.36$ & $6.59 \pm 0.09$ & $7.43 \pm 0.12$ & $15.98 \pm 0.74$ \\
\hline Suc & $1.20 \pm 0.11$ & $0.64 \pm 0.09$ & $0.40 \pm 0.02$ & $0.13 \pm 0.05$ & $0.55 \pm 0.12$ & $0.00 \pm 0.00$ & $0.00 \pm 0.00$ & $0.00 \pm 0.00$ & $0.00 \pm 0.00$ & $0.00 \pm 0.00$ & $0.00 \pm 0.00$ & $0.00 \pm 0.00$ \\
\hline Mal & $1.05 \pm 0.09$ & $1.56 \pm 0.08$ & $1.65 \pm 0.09$ & $1.87 \pm 0.03$ & $1.09 \pm 0.08$ & $1.11 \pm 0.065$ & $1.28 \pm 0.02$ & $1.28 \pm 0.08$ & $0.45 \pm 0.12$ & $1.31 \pm 0.13$ & $1.44 \pm 0.11$ & $1.65 \pm 0.09$ \\
\hline Total & $25.36 \pm 1.55$ & $34.34 \pm 1.49$ & $46.90 \pm 1.01$ & $33.88 \pm 1.62$ & $20.78 \pm 1.10$ & $24.99 \pm 0.91$ & $27.90 \pm 0.88$ & $22.79 \pm 0.88$ & $21.93 \pm 0.71$ & $22.37 \pm 1.17$ & $25.39 \pm 1.07$ & $35.74 \pm 1.99$ \\
\hline $\begin{array}{l}\text { Carbo- } \\
\text { hydrate }\end{array}$ & \multicolumn{12}{|c|}{ Oat bran } \\
\hline Xyl & $1.22 \pm 0.11$ & $1.39 \pm 0.12$ & $1.64 \pm 0.14$ & $1.87 \pm 0.07$ & $1.64 \pm 0.07$ & $3.15 \pm 0.11$ & $1.49 \pm 0.08$ & $1.86 \pm 0.03$ & $1.41 \pm 0.03$ & $1.39 \pm 0.05$ & $1.58 \pm 0.15$ & $1.84 \pm 0.09$ \\
\hline Ara & $1.08 \pm 0.09$ & $1.17 \pm 0.08$ & $1.10 \pm 0.08$ & $1.57 \pm 0.14$ & $0.00 \pm 0.08$ & $0.00 \pm 0.00$ & $0.00 \pm 0.00$ & $0.00 \pm 0.00$ & $1.28 \pm 0.08$ & $1.13 \pm 0.06$ & $1.10 \pm 0.06$ & $1.28 \pm 0.04$ \\
\hline Fru & $0.00 \pm 0.00$ & $0.00 \pm 0.00$ & $0.00 \pm 0.00$ & $0.00 \pm 0.00$ & $0.00 \pm 0.00$ & $0.00 \pm 0.00$ & $0.00 \pm 0.00$ & $0.00 \pm 0.00$ & $0.72 \pm 0.05$ & $0.79 \pm 0.13$ & $0.89 \pm 0.08$ & $0.97 \pm 0.15$ \\
\hline Glu & $56.58 \pm 1.90$ & $62.26 \pm 1.57$ & $59.46 \pm 1.23$ & $55.49 \pm 2.11$ & $7.00 \pm 0.32$ & $10.40 \pm 0.57$ & $12.64 \pm 0.36$ & $17.14 \pm 0.41$ & $13.90 \pm 0.63$ & $16.20 \pm 0.93$ & $20.35 \pm 0.12$ & $22.64 \pm 0.55$ \\
\hline Suc & $0.00 \pm 0.0$ & $0.36 \pm 0.08$ & $0.00 \pm 0.00$ & $0.00 \pm 0.00$ & $0.00 \pm 0.00$ & $1.10 \pm 0.13$ & $1.40 \pm 0.08$ & $1.60 \pm 0.12$ & $0.00 \pm 0.00$ & $0.00 \pm 0.00$ & $0.00 \pm 0.00$ & $0.00 \pm 0.00$ \\
\hline Mal & $0.59 \pm 0.12$ & $0.96 \pm 0.03$ & $0.96 \pm 0.07$ & $0.98 \pm 0.09$ & $0.31 \pm 0.07$ & $0.53 \pm 0.04$ & $0.52 \pm 0.08$ & $0.56 \pm 0.06$ & $0.42 \pm 0.09$ & $1.54 \pm 0.07$ & $2.21 \pm 0.13$ & $2.07 \pm 0.08$ \\
\hline Total & $59.47 \pm 2.22$ & $66.14 \pm 1.88$ & $63.16 \pm 1.52$ & $59.91 \pm 2.41$ & $8.96 \pm 0.54$ & $15.18 \pm 0.85$ & $16.05 \pm 0.60$ & $21.16 \pm 0.62$ & $17.73 \pm 0.88$ & $21.05 \pm 1.24$ & $26.12 \pm 0.54$ & $28.81 \pm 0.91$ \\
\hline
\end{tabular}

Note: Values are means \pm SD values of three replicates $(n=3)$. Xyl - Xylose, Ara - Arabinose, Fru - Fructose, Glu - Glucose, Suc - Sucrose, Mal -

Maltose. 
3.5. Release of Mono- and Disaccharides from Bran Using Enzyme-Assisted Hydrolysis of 10- and 30-fold Scale-Up Process

A 10- and 30-fold scale-up process was carried out using a bioreactor. The release of individual sugars has been analyzed after $48 \mathrm{~h}$ of $\mathrm{EH}$, since during further $24 \mathrm{~h}$ of the small-scale process due to the continuation in the hydrolytic activity of $\alpha$-L-arabinofuranosidase present in Viscozyme $\mathrm{L}$ an extensive reduction in arabinose content was observed in all bran hydrolysates. A scale-up process revealed a similar trend of individual sugars increasing after $48 \mathrm{~h}$ of $\mathrm{EH}$. The advantage of Viscoferm over other hydrolytic enzymes has been proven in both scale-up experiments at high solids load, though the amount released varied depending on the type of sugar analyzed. As is seen, the amount of arabinose in bran

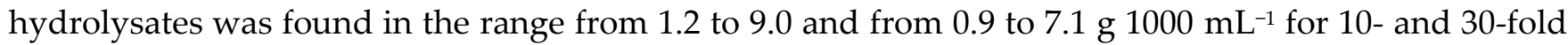
scale-up experiments, respectively. The highest arabinose content has been observed in rye bran hydrolysates underwent EH with Viscoferm and Viscozyme L, though it was 97.2 and 37.7\% higher than observed during small-scale EH, respectively (Figure 7A and 7D). As shown, the highest concentration of xylose monomer in both scale-up experiments was reached after $\mathrm{EH}$ with Celluclast $\mathrm{L}$, with rye bran having the highest content (Figure 7A and 7D), while oat bran the lowest (Figure 7C and 7F).

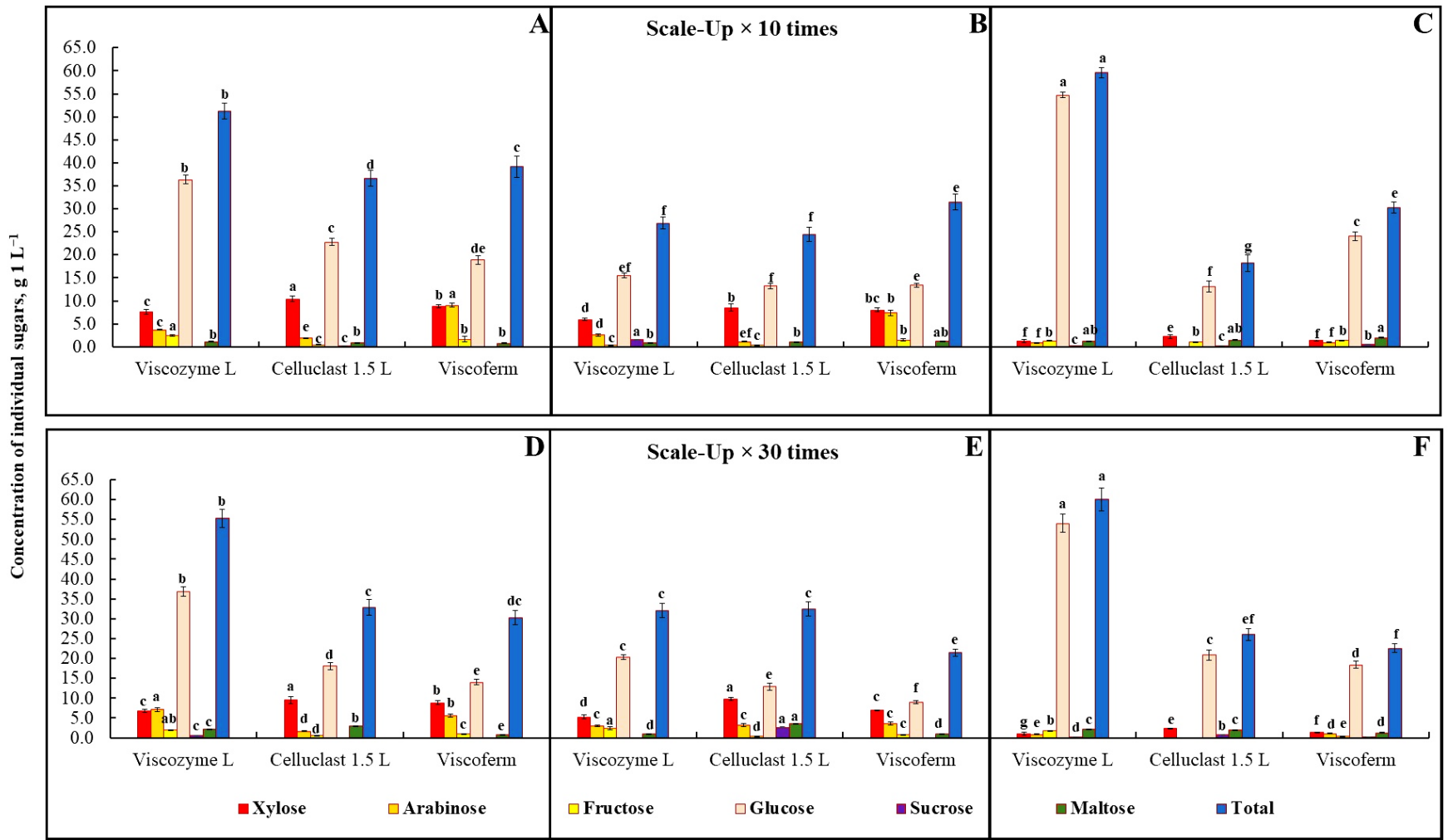

Figure 7. The release of mono- and disaccharides after enzymatic hydrolysis of rye (A, D), wheat (B, E), and oat $(\mathrm{C}, \mathrm{F})$ bran samples for $48 \mathrm{~h}$ with three multi-enzyme complexes, i.e., Viscozyme L, Celluclast 1.5 $\mathrm{L}$, and Viscoferm, g $1000 \mathrm{~mL}^{-1}$ of hydrolysate. Note: The process was done 10- and 30-fold scaled up process conditions. Note: Values are means \pm SD values of triplicates $(n=3)$. Means within the same sugar with different superscript letters $(\mathrm{a}, \mathrm{b}, \mathrm{c}, \mathrm{d})$ are significantly different at $p<0.05$.

The amount of xylose released was 18.6\% (10-fold) and 25.5\% (30-fold) lower than observed at smallscale rye bran EH. Viscozyme L demonstrated the lowest hydrolytic activity at high solids load in relation to xylose yield, which is possibly associated with high susceptibility of xylanase to external factors such as high content of other sugars monomers or availability of free bioactives that have exhibited inhibitory activities. However, assessing the glucose yield obtained in the scaled-up EH process, the superiority of Viscozyme L over other enzymes was highlighted for rye and wheat bran in comparison with small-scale EH experiment. The amounts of glucose obtained at both 10- and 30-fold 
scale-up conditions were 7.8-8.8\%, 19.0-38.3\%, and 8.0-9.1\% lower than released during small-scale EH of rye, wheat, and oat, respectively.

Evaluation of the total amount of sugars revealed lower release in both 10- and 30-fold scaled experiments than acquired during small-scale EH process, however, the proposed EH conditions are still valid, since the $100 \mathrm{~g}$ of enzymatically hydrolyzed rye, wheat, and oat could deliver up to 55.3, 32.5, and $60.0 \mathrm{~g}$ of sugars, respectively. In general, the highest total sugars yield was obtained during EH of bran with Viscozyme L, except for wheat (10-fold scale), where Viscoferm demonstrated relatively better hydrolytic performance. In the context of the non-waste technology, the mono- and disaccharides released have great potential to be used in bioethanol fuel production, however, a proper purification process needs to be developed $[37,55]$.

\subsection{Recovery of FA from Bran Hydrolysates}

In this experiment, the hydrolysates of rye bran acquired after EH with Viscozyme L were subjected to SPE purification using polymeric reversed-phase Strata X column (30 mg $\left.3 \mathrm{~mL}^{-1}\right)$. The selection of the sorbent was based on availability, effectiveness, and simplicity of use, since no specific activation, i.e., thermal, acidic, or base aside from conditioning with either $\mathrm{MeOH}$ or $\mathrm{EtOH}$ are required [56].

The solubility of FA can vary depending on the solvent and the concentration used. In the earlier report of Couteau et al. [57], positive desorption of FA from polyvinylpolypyrrolidone (PVPP) with a purity of about $62 \%$ was achieved by $96 \% \mathrm{EtOH}$, while later on, $97.4 \%$ recovery of FA has been demonstrated by $60 \% \mathrm{EtOH}$ [58]. The contradiction in results on recovery of FA using different concentrations of alcohol promoted the design of this experiment to study the recovery and purity of FA using $\mathrm{MeOH}$ and the less toxic $\mathrm{EtOH}$ and their aqueous solutions as elution solvents. The purity of FA in collected fractions was studied chromatographically by assessing the presence of side HCMs and mono- and disaccharides.

The results on FA recovery by means of $\mathrm{MeOH}$ and their aqueous solutions revealed increasing desorption of both $t$-FA and $t$-iso-FA in a MeOH concentration-dependent manner (Figure 8A). Up to 67.2 and $80.1 \%$ recovery of $t$-FA and $t$-iso-FA from rye bran hydrolysates was achieved by means of acidified $80 \% \mathrm{MeOH}$ ( $2 \%$ formic acid, $v / v)$, respectively. The overall purity of FA in the fraction collected was $82.7 \%$. Application of acidified $90 \% \mathrm{MeOH}$ brought a rise in the recovery of $t$-FA and $t$-iso-FA, since 70.6 and $83.6 \%$ of these HCMs were observed in the collected phase, but the relative purity of FA was $83.4 \%$. To improve the purity of FA, an additional wash-up step with $5 \% \mathrm{MeOH}$ was done after FA-rich hydrolysates were passed through the column and afterward eluted by $90 \% \mathrm{MeOH}$. This approach has brought up to $90.1 \%$ purity of FA with a relative recovery of $71.6 \%$. 


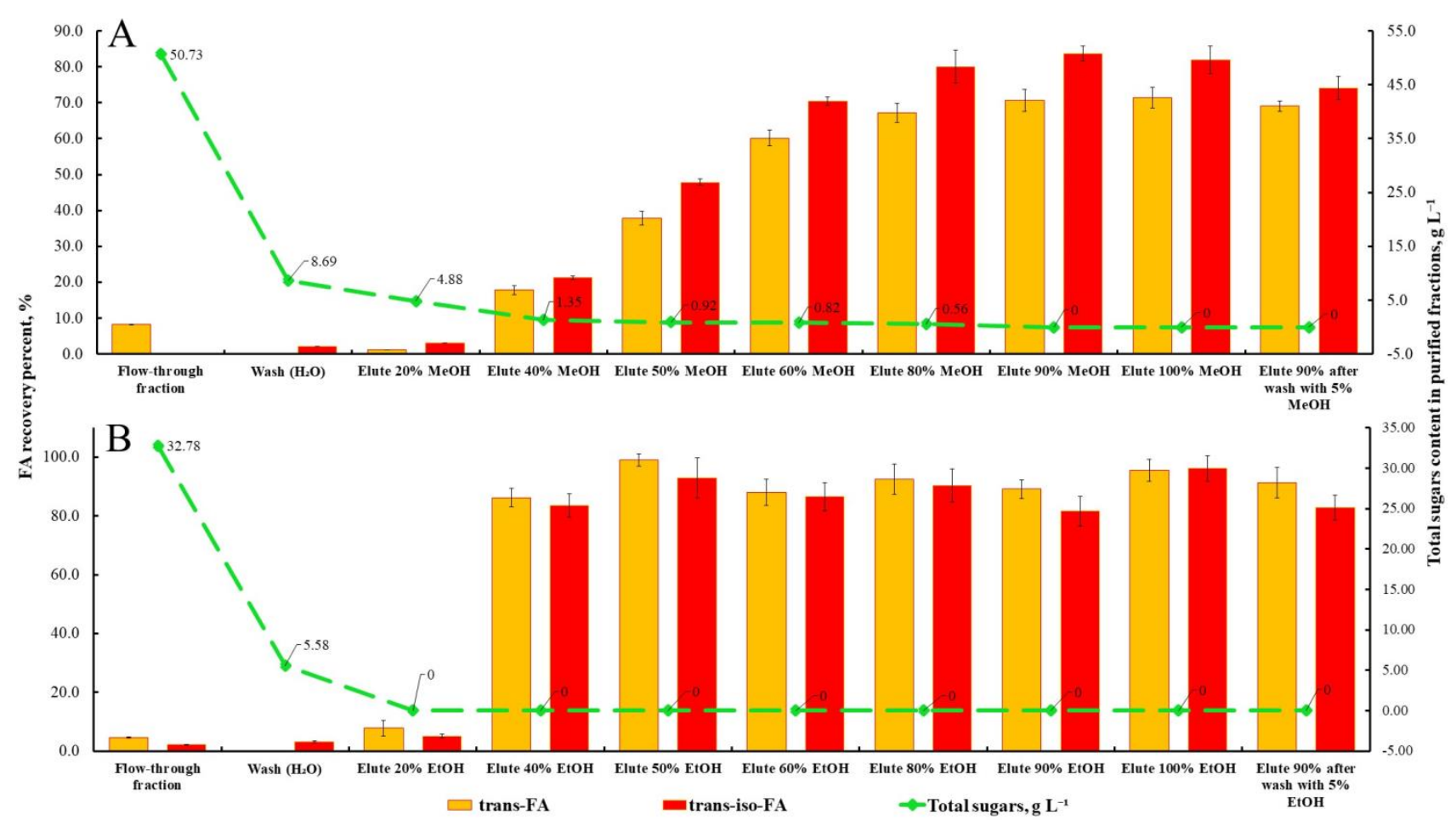

Figure 8. Recovery percentage of $t$-FA and $t$-iso-FA following solid-phase extraction by Strata $X$ column using $\mathrm{MeOH}(\mathrm{A})$ and $\mathrm{EtOH}(\mathrm{B})$ and their aqueous solutions as eluent. Note: Values are means $\pm \mathrm{SD}$ values of triplicates $(n=2)$. Green line on the plot indicates the residual concentration of sugars, $\mathrm{g} \mathrm{L}^{-1}$ in fractions collected.

Satisfactory results on recovery of FA from rye bran hydrolysates were obtained with the application of $\mathrm{EtOH}$ as eluent (Figure 8B). At the first step of purification, the 20 and $40 \% \mathrm{EtOH}$ were used to check the validity of these solvents for desorbing of FA retained on the stationary phase of Strata X column. As revealed, the selected concentrations of $\mathrm{EtOH}$ were found be to less effective in desorbing either $t$-FA or $t$-iso-FA from the polymer selected. However, the recovery of these two compounds was 67.5 and $97.5 \%$ more effective than achieved by $\mathrm{MeOH}$, respectively. An increase in $\mathrm{EtOH}$ concentration up to $50 \%$ resulted in a rise in the recovery of $t$-FA and $t$-iso-FA up to 99.1 and $92.9 \%$. Application of this eluting agent ensured $94.0 \%$ purity of FA obtained.

\subsection{Fatty Acid Composition of Brown Lipophilic Substance}

Buranov et al. [59] indicated in a report that the alkaline-derived hydrolysates of wheat and corn bran was contained a brown lipophilic substance that made the process of FA purification challenging. The presence of the brown substance has also been mentioned in a report by Salgado et al. [56], noting that it can be easily precipitated by adding $30 \% \mathrm{EtOH}$ to the alkali extract, followed by centrifugation. However, neither of the reports specified the composition of the waxy substance observed, therefore in the further section characterization of the lipophilic fraction will be given based on fatty acid (FTA) content (Table 6).

The results demonstrated significant variations in FTA percentage distribution between hydrolysis methods used. The abundance of unsaturated FTA was revealed for lipids obtained after EH of bran, making up $77-81 \%$ of the total FTA (in relative percentage), while $43-61 \%$ of unsaturated FTA were observed in lipids of alkaline-assisted hydrolysates. Linoleic acid (C18:2), oleic acid (C18:1), and palmitic acid (C16:0) contributed the most to the total amount of FTA, corresponding to about 93.0 to $98.0 \%$. The results on relative percentage of FTA in rye and wheat bran are consistent with data obtained by Cardoso et al. [60], noting that $\mathrm{C} 18: 2$, followed by $\mathrm{C} 18: 1, \mathrm{C} 16: 0$, and to a lesser extent $\mathrm{C} 18: 3$ are the most abundant FTA found. The amount of SFA in the lipid fraction of oat bran lipids varied in the range of $4.1-9.6 \%$, while PUFA was in the range of $39.4-46.3 \%$. C18:1 was found to be the most dominant fatty acid, the 
percentage of which was in the range of 13.1-29.0\%. A similar contribution of SFA to the total amount of FTA was reported for oat lipids after alkaline hydrolysis, followed by methylation in boron trifluoridemethanol [61]. A higher amount of PUFA was found in rye-derived lipids upon subjecting bran samples to EH with Celluclast $1.5 \mathrm{~L}$ and alkaline-assisted hydrolysis since the concentration was $16.0-23.7 \%$ and $18.7 \%$ higher than that observed in oat bran-derived lipids, respectively.

The total content of FTA in bran-derived lipids has been found to be hydrolysis method dependent

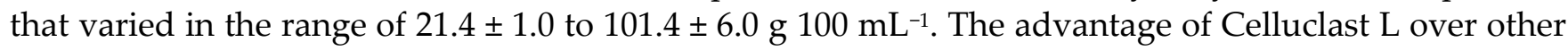
enzymes used in relation to FTA release from wheat bran samples was observed. The amount of FTA in wheat-derived lipids was found $289.9 \%$ higher than obtained by alkaline hydrolysis. Notably weaker, but still effective release of FTA from rye and wheat bran matrix was observed upon EH with Viscozyme L. EH of rye and wheat bran in comparison to alkaline-assisted hydrolysis has ensured the release of 68.4 \pm 7.8 and 51.3. $\pm 2.4 \mathrm{~g} 100 \mathrm{~mL}^{-1}$ of FTA, which is 160.9 and $87.8 \%$ more than alkaline hydrolysis does. The $\mathrm{EH}$ with Viscoferm in comparison to alkaline hydrolysis was able to release 25.4 and $18.8 \%$ more FTA from oat and wheat bran matrix, while no obvious effect was observed for rye bran.

In general, considering Viscozyme $\mathrm{L}$ and Viscoferm have higher declared xylanolytic activity than cellulolytic, which is also confirmed by Wikiera et al. [62], it can be assumed that the degradation of cellulose composed cell-wall membranes by means of cellulolytic enzymes is more important for the efficient release of FTA than by xylanolytic enzymes. 
Table 6. Fatty acid composition of bran hydrolysates according to the hydrolysis method.

\begin{tabular}{|c|c|c|c|c|c|c|c|c|c|}
\hline \multirow{3}{*}{$\begin{array}{c}\text { Type } \\
\text { of } \\
\text { Bran }\end{array}$} & \multirow{3}{*}{ HM } & \multicolumn{8}{|c|}{ Fatty acid, $\% w / v$} \\
\hline & & \multicolumn{2}{|c|}{ SFA } & \multicolumn{3}{|c|}{ MUFA } & \multicolumn{3}{|c|}{ PUFA } \\
\hline & & C16:0 & C18:0 & C18:1n9c & C18:1n9t & C20:1n9c & C18:2n6c & C18:3n3c & C20:3n3c \\
\hline \multirow{4}{*}{ Rye } & $\mathrm{KOH}(10 \%$ in $\mathrm{MeOH})$ & $5.46 \pm 0.06$ & $0.33 \pm 0.00$ & $4.18 \pm 0.19$ & nd & $0.06 \pm 0.01$ & $14.92 \pm 0.13$ & $1.27 \pm 0.04$ & $<\mathrm{LOQ}$ \\
\hline & Viscozyme L & $14.24 \pm 1.16$ & $0.89 \pm 0.13$ & $12.13 \pm 1.36$ & nd & $2.46 \pm 0.74$ & $36.10 \pm 1.24$ & $2.62 \pm 0.26$ & nd \\
\hline & Celluclast 1.5 L & $7.97 \pm 0.61$ & $0.37 \pm 0.09$ & $5.88 \pm 0.44$ & nd & nd & $22.72 \pm 0.26$ & $1.58 \pm 0.10$ & nd \\
\hline & Viscoferm & $4.39 \pm 0.10$ & $0.31 \pm 0.02$ & $3.22 \pm 0.34$ & nd & nd & $12.92 \pm 0.36$ & $0.59 \pm 0.20$ & nd \\
\hline \multirow{4}{*}{ Wheat } & $\mathrm{KOH}(10 \%$ in $\mathrm{MeOH})$ & $5.62 \pm 0.08$ & $0.38 \pm 0.02$ & $5.40 \pm 0.08$ & nd & $0.01 \pm 0.00$ & $14.80 \pm 0.68$ & $1.10 \pm 0.07$ & $0.02 \pm 0.01$ \\
\hline & Viscozyme L & $10.19 \pm 0.29$ & $0.67 \pm 0.06$ & $10.86 \pm 0.91$ & $0.05 \pm 0.02$ & $0.23 \pm 0.05$ & $27.00 \pm 0.99$ & $2.34 \pm 0.14$ & nd \\
\hline & Celluclast 1.5 L & $22.88 \pm 0.39$ & $1.22 \pm 0.01$ & $21.06 \pm 0.31$ & nd & nd & $57.09 \pm 0.42$ & $4.34 \pm 0.06$ & nd \\
\hline & Viscoferm & $6.80 \pm 0.30$ & $0.45 \pm 0.12$ & $6.64 \pm 0.30$ & nd & nd & $17.87 \pm 0.40$ & $0.72 \pm 0.03$ & nd \\
\hline \multirow{4}{*}{ Oat } & $\mathrm{KOH}(10 \%$ in $\mathrm{MeOH})$ & $7.12 \pm 0.05$ & $0.54 \pm 0.01$ & $13.15 \pm 0.66$ & nd & $0.12 \pm 0.01$ & $15.30 \pm 0.35$ & $0.54 \pm 0.10$ & nd \\
\hline & Viscozyme L & $12.37 \pm 1.35$ & $1.01 \pm 0.08$ & $29.02 \pm 3.75$ & nd & $0.43 \pm 0.05$ & $28.14 \pm 4.49$ & $1.10 \pm 0.19$ & nd \\
\hline & Celluclast 1.5 L & $12.20 \pm 0.25$ & $0.75 \pm 0.15$ & $27.88 \pm 0.27$ & nd & nd & $25.89 \pm 0.70$ & $0.66 \pm 0.28$ & nd \\
\hline & Viscoferm & $8.32 \pm 0.01$ & $0.66 \pm 0.08$ & $18.62 \pm 0.31$ & nd & nd & $18.35 \pm 0.38$ & $0.19 \pm 0.10$ & nd \\
\hline
\end{tabular}

Note: HM - hydrolysis method; SFA - saturated fatty acids; MUFA - monounsaturated fatty acids; PUFA - polyunsaturated fatty acids; nd - not detected; < LOQ - below limit of detection. 


\section{Conclusions}

The present study was undertaken to establish the hydrolytic ability of lignocellulose-degrading enzymes and release bound ferulic acid (FA) during enzymatic hydrolysis (EH) bran. For these purposes, three types of bran, i.e., rye, wheat, and oat were subjected to EH. The release of mono- and disaccharides, FA, and other hydroxycinnamates (HCMs) was monitored throughout the entire process of EH. For comparative purposes, the efficiency of EH in releasing FA along with alkaline-assisted hydrolysis was assessed by an online SFE-SFC-MS extraction approach. The process of small-scale EH revealed that each enzyme, due to its specificity and activity, contributed differently to the release of HCMs from bran matrix, though, among the enzymes tested, the advantage of Viscozyme L was highlighted. Overall, a gentler approach demonstrated up to $215.7 \%$ release of the total alkali-extractable FA (sum of $t$-FA and $t$-iso-FA) from rye bran, while 79.5, and $60.3 \%$ was released from wheat and oat bran, respectively. Favorable EH conditions during the scale-up process ensured comparable to smallscale process release of FA from rye and wheat bran. Up to 217.6 and $91.2 \%$ release of the total alkaliextractable FA was achieved from rye and wheat bran performing EH with Viscozyme L and Viscoferm, respectively. The introduced $\mathrm{SFE}-\mathrm{CO}_{2}-\mathrm{EtOH}$ extraction approach revealed a significantly higher release of FA, though the extractability varied depending on the parameters used. Extraction by $\mathrm{CO}_{2}$ and $10 \%$ $\mathrm{EtOH}$ as a co-solvent, $15 \mathrm{MPa}$ pressure, $50{ }^{\circ} \mathrm{C}$ temperature, and the length of the static and dynamic mode of 1 and 5 min was able to deliver by 164.0,69.9, and 329.9\% higher amount of FA than was obtained after alkaline-assisted hydrolysis of rye, wheat, and oat bran, respectively. The experimental results on recovery and purification demonstrated the applicability of styrene-divinylbenzene-based reversed-phase Strata $X$ column for removal of degradation product from bran hydrolysates. In the purified fraction, the absence of residual HCMs and carbohydrates has been confirmed, making recovered FA of $94.0 \%$ purity.

The scale-up process confirmed the validity of the technology for industrial-scale production, which altogether could be treated as a green alternative and could represent the future of sustainable FA production. 


\section{Author Contributions}

Conceptualization, V.R. and K.J.-R.; data curation, V.R.; formal analysis, V.R., J.K. and F.V.; funding acquisition, V.R.; investigation, V.R.; methodology, V.R., K.J.-R. and J.K.; project administration, K.J.-R.; resources, G.L. and A.V.; software, V.R.; visualization, V.R.; writing-original draft, V.R.; writingreview and editing, V.R. and D.L. All authors have read and agreed to the published version of the manuscript.

\section{Funding}

The present study was supported by the Latvian Council of Science under individual Project No. lzp-2020/2-0323 “Highly efficient release of ferulic acid from agro-industrial by-products by cellulosedegrading enzymes (FerulCelluZyms)".

\section{Data Availability Statement}

The data sets and analysis of current study are available from the corresponding author upon reasonable request.

\section{Conflicts of Interest}

The authors declare that they have no known competing financial interests or personal relationships that could have appeared to influence the work reported in this paper.

\section{References}

1. FAOSTAT Global crops production quantity Available online: https://www.fao.org/faostat/en/\#data/QCL (accessed on Oct 14, 2021).

2. Luithui, Y.; Baghya Nisha, R.; Meera, M.S. Cereal by-products as an important functional ingredient: effect of processing. J. Food Sci. Technol. 2019, 56, 1-11, doi:10.1007/s13197-018-3461-y.

3. Wang, G.; Huang, D.; Li, Y.; Wen, J.; Jia, X. A metabolic-based approach to improve xylose utilization for fumaric acid production from acid pretreated wheat bran by Rhizopus oryzae. Bioresour. Technol. 2015, 180, 119-127, doi:10.1016/j.biortech.2014.12.091.

4. Di Gioia, D.; Sciubba, L.; Setti, L.; Luziatelli, F.; Ruzzi, M.; Zanichelli, D.; Fava, F. Production of biovanillin from wheat bran. Enzyme Microb. Technol. 2007, 41, 498-505, doi:10.1016/j.enzmictec.2007.04.003.

5. Radenkovs, V.; Juhnevica-Radenkova, K.; Górnaś, P.; Seglina, D. Non-waste technology through the enzymatic hydrolysis of agro-industrial by-products. Trends Food Sci. Technol. 2018, 77, 64-76, doi:10.1016/j.tifs.2018.05.013.

6. Ferri, M.; Happel, A.; Zanaroli, G.; Bertolini, M.; Chiesa, S.; Commisso, M.; Guzzo, F.; Tassoni, A. Advances in combined enzymatic extraction of ferulic acid from wheat bran. N. Biotechnol. 2020, 56, 38-45, doi:10.1016/j.nbt.2019.10.010.

7. Martín-Diana, A.B.; Tomé-Sánchez, I.; García-Casas, M.J.; Martínez-Villaluenga, C.; Frías, J.; Rico, D. A novel strategy to produce a soluble and bioactive wheat bran ingredient rich in ferulic acid. Antioxidants 2021, 10, 1-24, doi:10.3390/antiox10060969.

8. Koistinen, V.M.; Katina, K.; Nordlund, E.; Poutanen, K.; Hanhineva, K. Changes in the phytochemical profile of rye bran induced by enzymatic bioprocessing and sourdough fermentation. Food Res. Int. 2016, 89, 1106-1115, doi:10.1016/j.foodres.2016.06.027.

9. Kapreliants, L.; Zhurlova, O. Technology of wheat and rye bran biotransformation into functional ingredients. Int. Food Res. J. 2017, 24, 1975-1979.

10. Gani, A.; Sm, W.; Fa, M.; Hameed, G. Whole-grain cereal bioactive compounds and their health benefits : A review. J. Food Process. Technol. 2012, 3, doi:10.4172/2157-7110.1000146.

11. Konopka, I.; Tańska, M.; Faron, A.; Czaplicki, S. Release of free ferulic acid and changes in 
antioxidant properties during the wheat and eye bread making process. Food Sci. Biotechnol. 2014, 23, 831-840, doi:10.1007/s10068-014-0112-6.

12. Andreasen, M.F.; Christensen, L.P.; Meyer, A.S. Content of phenolic acids and ferulic acid dehydrodimers in 17 rye (Secale cereale L .) varieties. J. Agric. Food Chem. 2000, 48, 2837-2842.

13. Buksa, K.; Praznik, W.; Loeppert, R.; Nowotna, A. Characterization of water and alkali extractable arabinoxylan from wheat and rye under standardized conditions. J. Food Sci. Technol. 2016, 53, 1389-1398, doi:10.1007/s13197-015-2135-2.

14. Juhnevica-Radenkova, K.; Kviesis, J.; Moreno, D.A.; Seglina, D.; Vallejo, F.; Valdovska, A.; Radenkovs, V. Highly-efficient release of ferulic acid from agro-industrial by-products via enzymatic hydrolysis with cellulose-degrading enzymes: Part I-the superiority of hydrolytic enzymes versus conventional hydrolysis. Foods 2021, 10, doi:10.3390/foods10040782.

15. Martínez-Villaluenga, C.; Peñas, E. Health benefits of oat: current evidence and molecular mechanisms. Curr. Opin. Food Sci. 2017, 14, 26-31, doi:10.1016/j.cofs.2017.01.004.

16. Mattila, P.; Pihlava, J.-H.; Hellström, H. Contents of phenolic acids, alkyl- and alkenylresorcinols, and avenanthramides in commercial grain products. J. Agric. Food Chem. 2005, 53, 8290-8295.

17. Zhao, Z.; Moghadasian, M.H. Chemistry, natural sources, dietary intake and pharmacokinetic properties of ferulic acid: A review. Food Chem. 2008, 109, 691-702, doi:10.1016/j.foodchem.2008.02.039.

18. Radenkovs, V.; Kviesis, J.; Juhnevica-Radenkova, K.; Valdovska, A.; Püssa, T.; Klavins, M.; Drudze, I. Valorization of wild apple (Malus spp.) by-products as a source of essential fatty acids, tocopherols and phytosterols with antimicrobial activity. Plants 2018, 7, doi:10.3390/plants7040090.

19. Ruiz, R.P. Gravimetric measurements of water. In Handbook of food analytical chemistry, water, proteins, enzymes, lipids, and carbohydrates; Wrolstad, R.E., Acree, T.E., Decker, E.A., Penner, M.H., Reid, D.S., Schwartz, S.J., Shoemaker, C.F., Smith, D., Sporns, P., Eds.; John Wiley and Sons Inc.,: New Jersey, 2005; pp. 5-33 ISBN 9780471709084.

20. American society for testing and materials Standard test methods for fatty and rosin acids in tall oil fractionation products by capillary gas chromatography. Annu. B. ASTM Stand. 2001, 96, 1-3.

21. Kumar, N.; Pruthi, V. Potential applications of ferulic acid from natural sources. Biotechnol. Reports 2014, 4, 86-93, doi:10.1016/j.btre.2014.09.002.

22. de Paiva, L.B.; Goldbeck, R.; dos Santos, W.D.; Squina, F.M. Ferulic acid and derivatives: Molecules with potential application in the pharmaceutical field. Brazilian J. Pharm. Sci. 2013, 49.

23. Palafox-Carlos, H.; Ayala-Zavala, J.F.; González-Aguilar, G.A. The role of dietary fiber in the bioaccessibility and bioavailability of fruit and vegetable antioxidants. J. Food Sci. 2011, 76, 6-15, doi:10.1111/j.1750-3841.2010.01957.x.

24. European Council Directive 2010/75/EU Industrial Emissions. Off. J. Eur. Union 2010, L334, 17-119, doi:10.3000/17252555.L_2010.334.eng.

25. Ohra-Aho, T.; Niemi, P.; Aura, A.M.; Orlandi, M.; Poutanen, K.; Buchert, J.; Tamminen, T. Structure of brewer's spent grain lignin and its interactions with gut microbiota in vitro. J. Agric. Food Chem. 2016, 64, 812-820, doi:10.1021/acs.jafc.5b05535.

26. Mahmoudi, H.; Marzouki, M.; M'Rabet, Y.; Mezni, M.; Ait Ouazzou, A.; Hosni, K. Enzyme pretreatment improves the recovery of bioactive phytochemicals from sweet basil (Ocimum basilicum L.) leaves and their hydrodistilled residue by-products, and potentiates their biological activities. Arab. J. Chem. 2020, 13, 6451-6460, doi:10.1016/j.arabjc.2020.06.003.

27. Tang, Y.; Hao, J.; Fan, C.; Cao, X. Preparative separation of high-purity trans- and cis-ferulic acid from wheat bran by $\mathrm{pH}$-zone-refining counter-current chromatography. J. Chromatogr. A 2021, 1636, 461772, doi:10.1016/j.chroma.2020.461772. 
28. Schär, M.Y.; Corona, G.; Soycan, G.; Dine, C.; Kristek, A.; Alsharif, S.N.S.; Behrends, V.; Lovegrove, A.; Shewry, P.R.; Spencer, J.P.E. Excretion of avenanthramides, phenolic acids and their major metabolites following intake of oat bran. Mol. Nutr. Food Res. 2018, 62, doi:10.1002/mnfr.201700499.

29. Rybka K, Sitarski J, R.-B.K. Ferulic acid in rye and wheat grain and grain dietary fiber. Cereal Chem. 1993, 70, 55-59.

30. Zhang, J.; Ding, Y.; Dong, H.; Hou, H.; Zhang, X. Distribution of phenolic acids and antioxidant activities of different bran fractions from three pigmented wheat varieties. J. Chem. 2018, 2018, doi:10.1155/2018/6459243.

31. Guo, W.; Beta, T. Phenolic acid composition and antioxidant potential of insoluble and soluble dietary fibre extracts derived from select whole-grain cereals. Food Res. Int. 2013, 51, 518-525, doi:10.1016/j.foodres.2013.01.008.

32. Li, X.; Lin, J.; Gao, Y.; Han, W.; Chen, D. Antioxidant activity and mechanism of Rhizoma cimicifugae. Chem. Cent. J. 2012, 6, 1-10, doi:10.1186/1752-153X-6-140.

33. Lee, J.E.; Kim, B.B.; Ko, Y.; Jeong, S.H.; Park, J.B. Effects of Cimicifugae rhizoma on the osteogenic and adipogenic differentiation of stem cells. Exp. Ther. Med. 2017, 13, 443-448, doi:10.3892/etm.2016.4010.

34. Li, J.-X.; Yu, Z.-Y. Cimicifugae rhizoma: From origins, bioactive constituents to clinical outcomes. Curr. Med. Chem. 2006, 13, 2927-2951, doi:10.2174/092986706778521869.

35. Kaszuba, J.; Kapusta, I.; Posadzka, Z. Content of phenolic acids in the grain of selected polish triticale cultivars and its products. Molecules 2021, 26, doi:10.3390/molecules26030562.

36. Achinivu, E.C.; Flourat, A.L.; Brunissen, F.; Allais, F. Valorization of waste biomass from oleaginous "oil-bearing" seeds through the biocatalytic production of sinapic acid from mustard bran. Biomass and Bioenergy 2021, 145, 105940, doi:10.1016/j.biombioe.2020.105940.

37. Kuhn, E.M.; O'Brien, M.H.; Ciesielski, P.N.; Schell, D.J. Pilot-scale batch alkaline pretreatment of corn stover. ACS Sustain. Chem. Eng. 2016, 4, 944-956, doi:10.1021/acssuschemeng.5b01041.

38. Morales-Huerta, J.C.; Hernández-Meléndez, O.; Hernández-Luna, M.G.; Manero, O.; Bárzana, E.; Vivaldo-Lima, E. An experimental and modeling study on the pretreatment and alkaline hydrolysis of blue agave bagasse in twin-screw extruders. Ind. Eng. Chem. Res. 2021, 60, 1244912460, doi:10.1021/acs.iecr.1c02175.

39. Ruiz, H.A.; Conrad, M.; Sun, S.N.; Sanchez, A.; Rocha, G.J.M.; Romaní, A.; Castro, E.; Torres, A.; Rodríguez-Jasso, R.M.; Andrade, L.P.; et al. Engineering aspects of hydrothermal pretreatment: From batch to continuous operation, scale-up and pilot reactor under biorefinery concept. Bioresour. Technol. 2020, 299, 122685, doi:10.1016/j.biortech.2019.122685.

40. Zuorro, A.; Iannone, A.; Lavecchia, R. Water-organic solvent extraction of phenolic antioxidants from brewers' spent grain. Processes 2019, 7, doi:10.3390/pr7030126.

41. Gammoh, S.; Alu'datt, M.H.; Alhamad, M.N.; Rababah, T.; Ereifej, K.; Almajwal, A.; Ammari, Z.A.; Al Khateeb, W.; Hussein, N.M. Characterization of phenolic compounds extracted from wheat protein fractions using high-performance liquid chromatography/liquid chromatography mass spectrometry in relation to anti-allergenic, anti-oxidant, anti-hypertension, and anti-diabetic propertie. Int. J. Food Prop. 2017, 20, 2383-2395, doi:10.1080/10942912.2016.1238832.

42. Zavala-López, M.; García-Lara, S. An improved microscale method for extraction of phenolic acids from maize. Plant Methods 2017, 13, 1-11, doi:10.1186/s13007-017-0235-x.

43. Ameer, K.; Shahbaz, H.M.; Kwon, J.H. Green extraction methods for polyphenols from plant matrices and their byproducts: A review. Compr. Rev. Food Sci. Food Saf. 2017, 16, 295-315, doi:10.1111/1541-4337.12253.

44. Pinto, T.I.; Coelho, J.A.; Pires, B.I.; Neng, N.R.; Nogueira, J.M.; Bordado, J.C.; Sardinha, J.P. Supercritical carbon dioxide extraction, antioxidant activity, and fatty acid composition of bran 
oil from rice varieties cultivated in Portugal. Separations 2021, 8, doi:10.3390/separations8080115.

45. Ghafoor, K.; AL-Juhaimi, F.Y.; Choi, Y.H. Supercritical fluid extraction of phenolic compounds and antioxidants from grape (Vitis labrusca B.) seeds. Plant Foods Hum. Nutr. 2012, 67, 407-414, doi:10.1007/s11130-012-0313-1.

46. Kraujalis, P.; Kraujalienè, V.; Kazernavičiūtè, R.; Venskutonis, P.R. Supercritical carbon dioxide and pressurized liquid extraction of valuable ingredients from Viburnum opulus pomace and berries and evaluation of product characteristics. J. Supercrit. Fluids 2017, 122, 99-108, doi:10.1016/j.supflu.2016.12.008.

47. González, G.; Salvadó, J.; Montané, D. Reactions of vanillic acid in sub- and supercritical water. J. Supercrit. Fluids 2004, 31, 57-66, doi:10.1016/j.supflu.2003.09.015.

48. Junior, M.R.M.; Leite, A.V.; Dragano, N.R.V. Supercritical fluid extraction and stabilization of phenolic compounds from natural sources - Review (supercritical extraction and stabilization of phenolic compounds). Open Chem. Eng. J. 2014, 4, 51-60, doi:10.2174/1874123101004010051.

49. Luque de Castro, M..; Valcarcel, M.; Tena, M.. Analytical applications for supercritical fluid extraction. In Analytical supercritical fuid extraction; Springer, Berlin, Heidelberg: Heidelberg, 1994 ISBN 9783642786730.

50. Shin, H.-D.; McClendon, S.; Le, T.; Taylor, F.; Chen, R.R. A Complete enzymatic recovery of ferulic acid from corn residues with extracellular enzymes from Neosartorya spinosa NRRL185. Biotechnol. Bioeng. 2006, 20(95), 1108-1115, doi:10.1002/bit.21056.

51. Gama, R.; Van Dyk, J.S.; Pletschke, B.I. Optimisation of enzymatic hydrolysis of apple pomace for production of biofuel and biorefinery chemicals using commercial enzymes. 3 Biotech 2015, 5, 1075-1087, doi:10.1007/s13205-015-0312-7.

52. Xin, D.; Chen, X.; Wen, P.; Zhang, J. Insight into the role of $\alpha$-arabinofuranosidase in biomass hydrolysis: Cellulose digestibility and inhibition by xylooligomers. Biotechnol. Biofuels 2019, 12, 111, doi:10.1186/s13068-019-1412-0.

53. Bautista-Expósito, S.; Tomé-Sánchez, I.; Martín-Diana, A.B.; Frias, J.; Peñas, E.; Rico, D.; Casas, M.J.G.; Martínez-Villaluenga, C. Enzyme selection and hydrolysis under optimal conditions improved phenolic acid solubility, and antioxidant and anti-inflammatory activities of wheat bran. Antioxidants 2020, 9, 1-22, doi:10.3390/antiox9100984.

54. Alrahmany, R.; Avis, T.J.; Tsopmo, A. Treatment of oat bran with carbohydrases increases soluble phenolic acid content and influences antioxidant and antimicrobial activities. Food Res. Int. 2013, 52, 568-574, doi:10.1016/j.foodres.2013.03.037.

55. Wang, X.; Li, X.; Chen, D. Evaluation of antioxidant activity of isoferulic acid in vitro. Nat. Prod. Commun. 2011, 6, 1285-1288, doi:10.1177/1934578x1100600919.

56. Salgado, J.M.; Max, B.; Rodríguez-Solana, R.; Domínguez, J.M. Purification of ferulic acid solubilized from agroindustrial wastes and further conversion into 4-vinyl guaiacol by Streptomyces setonii using solid state fermentation. Ind. Crops Prod. 2012, 39, 52-61, doi:10.1016/j.indcrop.2012.02.014.

57. Couteau, D.; Mathaly, P. Purification of ferulic acid by adsorption after enzymic release from a sugar-beet pulp extract. Ind. Crops Prod. 1997, 6, 237-252, doi:10.1016/S0926-6690(97)00014-9.

58. Guo, T.; Sun, Y.; Sui, Y.; Li, F. Determination of ferulic acid and adenosine in Angelicae radix by micellar electrokinetic chromatography. Anal. Bioanal. Chem. 2003, 375, 840-843, doi:10.1007/s00216-003-1794-4.

59. Buranov, A.U.; Mazza, G. Extraction and purification of ferulic acid from flax shives, wheat and corn bran by alkaline hydrolysis and pressurised solvents. Food Chem. 2009, 115, 1542-1548, doi:10.1016/j.foodchem.2009.01.059.

60. Cardoso, R.V.C.; Fernandes, Â.; Pinela, J.; Dias, M.I.; Pereira, C.; Pires, T.C.S.P.; Carocho, M.; 
Vasallo, E.F.; Ferreira, I.C.F.R.; Barros, L. Valorization of cereal by-products from the milling industry as a source of nutrients and bioactive compounds to boost resource-use efficiency. Agronomy 2021, 11, doi:10.3390/agronomy11050972.

61. Yilmaz, I.; Dağlioğlu, O. The effect of replacing fat with oat bran on fatty acid composition and physicochemical properties of meatballs. Meat Sci. 2003, 65, 819-823, doi:10.1016/S03091740(02)00286-3.

62. Wikiera, A.; Mika, M.; Grabacka, M. Multicatalytic enzyme preparations as effective alternative to acid in pectin extraction. Food Hydrocoll. 2015, 44, 156-161, doi:10.1016/j.foodhyd.2014.09.018. 